\title{
An Assessment of Direct Radiative Forcing, Radiative Adjustments, and Radiative Feedbacks in Coupled Ocean-Atmosphere Models*
}

\author{
Eui-SeOK CHUNG AND BRIAN J. SODEN \\ Rosenstiel School of Marine and Atmospheric Science, University of Miami, Miami, Florida
}

(Manuscript received 25 June 2014, in final form 11 February 2015)

\begin{abstract}
In this study, radiative kernels are used to separate direct radiative forcing from radiative adjustments to that forcing to quantify the magnitude and intermodel spread of tropospheric and stratospheric adjustments in coupled ocean-atmosphere climate models. Radiative feedbacks are also quantified and separated from radiative forcing by assuming that feedbacks are a linear response to changes in global-mean surface temperature. The direct radiative forcing due to a quadrupling of $\mathrm{CO}_{2}$ is found to have an intermodel spread of $\sim 3 \mathrm{~W} \mathrm{~m}^{-2}$. In contrast to previous studies, relatively small estimates of cloud adjustments are obtained, which are both positive and negative. This discrepancy is at least partially attributable to small, but nonnegligible, global-mean surface warming in fixed sea surface temperature experiments, which aliases a surface-driven feedback response into estimates of the adjustments. This study suggests that correcting for the bias induced from this global-mean surface warming offers a more accurate estimate of tropospheric adjustments. It is shown that the regional patterns in the tropospheric adjustments tend to oppose the radiative feedback. This compensation is closely tied to spatial inhomogeneities in the initial rate of surface warming, suggesting that a substantial part of the spatial variation in the estimated tropospheric adjustment is an artifact of the linear regression methodology. Even when assuming that the global-mean estimates of the tropospheric adjustments are valid, neglecting them introduces little uncertainty in estimates of the total forcing, feedback, or effective climate sensitivity relative to the intermodel spread in these values.
\end{abstract}

\section{Introduction}

Climate feedbacks amplify or dampen the initial radiative perturbation induced by a forcing agent through changes in climate variables in response to global-mean surface temperature change. Intermodel differences in climate feedbacks are widely accepted as the primary cause for intermodel spread in the projected future climate changes in response to imposed radiative forcings (e.g., Cess et al. 1990; Zhang et al. 1994; Colman 2003; Bony et al. 2006). However, model-projected climate changes also differ because of discrepancies in the calculated radiative forcings by the models from specified

\footnotetext{
* Supplemental information related to this paper is available at the Journals Online website: http://dx.doi.org/10.1175/JCLI-D-14-00436.s1.

Corresponding author address: Eui-Seok Chung, Rosenstiel School of Marine and Atmospheric Science, University of Miami, 4600 Rickenbacker Causeway, Miami, FL 33149.

E-mail: echung@rsmas.miami.edu
}

trace gas concentrations (e.g., Andrews et al. 2012; Forster et al. 2013; Webb et al. 2013). Therefore, analyzing discrepancies in the characteristics of radiative forcings is important to increasing the credibility of climate change projections.

It has been argued that rapid adjustments may occur in the troposphere in response to imposed forcing agents and that these adjustments occur independently of the surface warming (e.g., Gregory et al. 2004; Gregory and Webb 2008; Colman and McAvaney 2011; Andrews et al. 2012; Webb et al. 2013). In particular, rapid cloud adjustments to an instantaneous $\mathrm{CO}_{2}$ increase have been identified to induce substantial radiative flux perturbations at the top of the atmosphere (e.g., Gregory and Webb 2008; Andrews and Forster 2008; Colman and McAvaney 2011; Zelinka et al. 2013; Vial et al. 2013; Block and Mauritsen 2013). It has been further suggested that diagnosed differences in climate feedbacks might be more correctly attributed to differences in the rapid adjustments and, thus, require an adequate method by which the rapid radiative adjustments can be 
accurately isolated from the corresponding radiative feedbacks, which develop in response to the resulting surface temperature changes.

Because the evaluation of the instantaneous forcing through radiative transfer calculations is not able to quantify the adjustment terms, fixed sea surface temperature (SST) experiments have been designed in which sea surface temperatures are constrained to a control state in order to inhibit climate feedback processes (e.g., Hansen et al. 2005; Held et al. 2010; Andrews 2014). The top of the atmosphere (TOA) radiative flux imbalance in the fixed SST experiments is the sum of the direct radiative forcing and rapid adjustments. Alternatively, for instantaneous $\mathrm{CO}_{2}$ increase experiments, a regression method has been proposed based on a relationship between TOA radiative fluxes and surface temperature (Gregory et al. 2004). Global-mean TOA flux is regressed in this method against global-mean surface temperature change, in which the resultant slope and $y$ intercept represent the climate sensitivity and the total radiative forcing, respectively. This method also uses the cloud radiative effect (CRE; i.e., the difference between totalsky and clear-sky net downward radiative fluxes at the TOA) to evaluate an approximation of cloud feedback. However, these efficient methods have difficulties in quantifying the direct radiative forcing and individual components of the rapid adjustments separately.

The radiative kernel technique was introduced to analyze climate feedback processes consistently among climate models (Soden and Held 2006; Soden et al. 2008; Shell et al. 2008). Radiative kernels describe differential response of the TOA radiative fluxes to incremental changes in feedback variables. Therefore, the use of radiative kernels can help diagnose discrepancies in transient climate response among climate models by enabling one to accurately decompose TOA radiative flux imbalances. Using radiative kernels in combination with a conventional finite-differencing approach (i.e., the model response $\Delta x$ for a variable $x$ is computed by subtracting the unperturbed control climate from the projected perturbed climate), Vial et al. (2013) estimated the magnitude and intermodel spread of tropospheric adjustments to an instantaneous $\mathrm{CO}_{2}$ quadrupling from atmosphereonly experiments in which climatological sea surface temperature and sea ice concentration are imposed. Since there is no constraint on land surface, however, small but nonnegligible global-mean surface warming in fixed SST experiments may alias a surface-driven feedback response into estimates of tropospheric adjustments.

By combining the radiative kernel method with a regression approach (Gregory et al. 2004), Block and Mauritsen (2013) quantified the magnitude of radiative feedbacks and corresponding adjustments in one coupled ocean-atmosphere model. Because of the nonlinear behavior of that model, they conducted piecewise linear regressions on the first $20 \mathrm{yr}$ and the last $130 \mathrm{yr}$ of an instantaneous $\mathrm{CO}_{2}$ quadrupling experiment, resulting in two substantially different forcing-feedback pairs. As Block and Mauritsen (2013) acknowledged, the division of the whole time period of the simulations into two subperiods is arbitrary and could be different across models. Furthermore, a period of $20 \mathrm{yr}$ may not be long enough for a robust regression analysis because of internal variability on seasonal-to-subdecadal time scales.

In this study, radiative kernels are also used, as in Vial et al. (2013) and Block and Mauritsen (2013), to quantify direct radiative forcing, rapid radiative adjustments to that forcing, and radiative feedbacks for coordinated coupled ocean-atmosphere model integrations of an instantaneous $\mathrm{CO}_{2}$ quadrupling. This study is similar to that of Block and Mauritsen (2013) in that radiative kernels are combined with a regression approach (Gregory et al. 2004), while a finite-differencing approach is used in Vial et al. (2013). However, unlike Block and Mauritsen (2013), who conducted piecewise linear regressions, we conduct linear regressions over the entire period of the experiment and attempt to examine the influence of global-mean surface warming in fixed SST experiments on the estimates of tropospheric adjustments. The relative importance of these components to effective climate sensitivity is also assessed to determine which processes are most responsible for intermodel differences in projected climate changes. We show that while the intermodel spread in effective climate sensitivity is dominated by uncertainties in the tropospheric feedbacks, there are significant correlations between the feedbacks, heat uptake, and radiative forcing that reduce the spread in the effective sensitivity of the models. In addition, we explore the applicability of this methodology to more realistic forcing scenarios.

\section{Method}

\section{a. Decomposition of TOA radiative flux perturbations}

For small climate changes for which the linear assumptions are valid, the net radiative flux imbalance at the TOA for clear-sky conditions $\left(\Delta R^{0}\right)$ can be decomposed into radiative flux perturbations associated with changes in climate variables in the troposphere and stratosphere and the direct radiative forcing from a forcing agent at the TOA $\left(\mathrm{DIR}^{0}\right)$, as follows: 


$$
\begin{aligned}
\Delta R^{0}= & \Delta R_{\mathrm{Tr}, T}^{0}+\Delta R_{\mathrm{Tr}, \mathrm{WV}}^{0}+\Delta R_{\mathrm{Tr}, a}^{0}+\Delta R_{\mathrm{St}, T}^{0} \\
& +\Delta R_{\mathrm{St}, \mathrm{WV}}^{0}+\mathrm{DIR}^{0} \\
= & K_{\mathrm{Tr}, T}^{0} \Delta T_{\mathrm{Tr}}+K_{\mathrm{Tr}, \mathrm{WV}}^{0} \Delta \mathrm{WV}_{\mathrm{Tr}}+K_{\mathrm{Tr}, a}^{0} \Delta a_{\mathrm{Tr}} \\
& +K_{\mathrm{St}, T}^{0} \Delta T_{\mathrm{St}}+K_{\mathrm{St}, \mathrm{WV}}^{0} \Delta \mathrm{WV}_{\mathrm{St}}+\mathrm{DIR}^{0},
\end{aligned}
$$

where $T, \mathrm{WV}, a, \mathrm{Tr}$, and St denote temperature, water vapor, surface albedo, troposphere (including the surface for temperature and surface albedo), and stratosphere, respectively. The radiative flux perturbations due to changes in climate variables in the troposphere and stratosphere for clear-sky conditions are computed here by multiplying the changes of temperature, water vapor, and surface albedo with the corresponding radiative kernel $\left(K^{0}\right)$ (e.g., Soden et al. 2008). The level of the tropopause is determined by analyzing the vertical distribution of the lapse rate following the World Meteorological Organization definition (e.g., Hansen et al. 2005). Such decomposition allows one to determine the direct clearsky radiative forcing from the imposed forcing agent $\left(\mathrm{DIR}^{0}\right)$. In other words,

$$
\begin{aligned}
\mathrm{DIR}^{0}= & \Delta R^{0}-\left(K_{\mathrm{Tr}, T}^{0} \Delta T_{\mathrm{Tr}}+K_{\mathrm{Tr}, \mathrm{WV}}^{0} \Delta \mathrm{WV}_{\mathrm{Tr}}\right. \\
& \left.+K_{\mathrm{Tr}, a}^{0} \Delta a_{\mathrm{Tr}}+K_{\mathrm{St}, T}^{0} \Delta T_{\mathrm{St}}+K_{\mathrm{St}, \mathrm{WV}}^{0} \Delta \mathrm{WV}_{\mathrm{St}}\right) .
\end{aligned}
$$

In Eq. (2), it is actually the logarithm of the water vapor change that is important for linear radiation dependence. It is also noted that Eq. (2) includes all perturbations of these variables, whether rapid adjustments or not.

As described in the introduction, changes in temperature, water vapor, and surface albedo at a given time of the experiment can be calculated in two ways: that is, a finite-differencing method and a linear regression method. In the finite-differencing method, all the changes in temperature, water vapor, and surface albedo relative to a control state are regarded as feedback processes. In contrast, the linear regression method uses only the portion of changes directly correlated with the global-mean surface (air) temperature changes to compute radiative flux perturbations associated with feedback processes. In other words, the regression method splits the total changes in temperature $(\Delta T)$, water vapor $(\Delta \mathrm{WV})$, and surface albedo $(\Delta a)$ into two parts (i.e., the linear and nonlinear portions) before calculating the flux anomalies. Consequently, the radiative flux perturbations arising from the nonlinear portion are considered as a rapid adjustment to the given forcing agent. Thus, Eq. (1), which describes the decomposition of the clear-sky TOA net radiative flux imbalance, is modified in the linear regression framework as follows:

$$
\begin{aligned}
\Delta R^{0}= & K_{\mathrm{Tr}, T}^{0}\left(\frac{d T}{d \bar{T}_{s}} \Delta \overline{T_{s}}\right)_{\mathrm{Tr}}+K_{\mathrm{Tr}, \mathrm{WV}}^{0}\left(\frac{d \mathrm{WV}}{d \overline{T_{s}}} \Delta \overline{T_{s}}\right)_{\mathrm{Tr}}+K_{\mathrm{Tr}, a}^{0}\left(\frac{d a}{d \overline{T_{s}}} \Delta \overline{T_{s}}\right)_{\mathrm{Tr}} \\
& +K_{\mathrm{Tr}, T}^{0}\left[\Delta T_{\mathrm{Tr}}-\left(\frac{d T}{d \bar{T}_{s}} \Delta \overline{T_{s}}\right)_{\mathrm{Tr}}\right]+K_{\mathrm{Tr}, \mathrm{WV}}^{0}\left[\Delta \mathrm{WV}_{\mathrm{Tr}}-\left(\frac{d \mathrm{WV}}{d \overline{T_{s}}} \Delta \overline{T_{s}}\right)_{\mathrm{Tr}}\right]+K_{\mathrm{Tr}, a}^{0}\left[\Delta a_{\mathrm{Tr}}-\left(\frac{d a}{d \bar{T}_{s}} \Delta \overline{T_{s}}\right)_{\mathrm{Tr}}\right] \\
& +K_{\mathrm{St}, T}^{0}\left(\frac{d T}{d \bar{T}_{s}} \Delta \overline{T_{s}}\right)_{\mathrm{St}}+K_{\mathrm{St}, \mathrm{WV}}^{0}\left(\frac{d \mathrm{WV}}{d \overline{T_{s}}} \Delta \bar{T}_{s}\right)_{\mathrm{St}} \\
& +K_{\mathrm{St}, T}^{0}\left[\Delta T_{\mathrm{St}}-\left(\frac{d T}{d \bar{T}_{s}} \Delta \bar{T}_{s}\right)_{\mathrm{St}}\right]+K_{\mathrm{St}, \mathrm{WV}}^{0}\left[\Delta \mathrm{WV}_{\mathrm{St}}-\left(\frac{d \mathrm{WV}}{d \overline{T_{s}}} \Delta \bar{T}_{s}\right)_{\mathrm{St}}\right]+\mathrm{DIR}^{0} .
\end{aligned}
$$

In Eq. (3), the regression slopes (e.g., $d T / d \overline{T_{s}}$ ) are computed at each point (two-dimensional for surface albedo and three-dimensional for temperature and water vapor) over the whole period of the simulations. The regression slopes are then multiplied by the change in global-mean surface temperature to determine the evolution of annual changes directly correlated with the global-mean surface temperature change \{e.g., $\left.\left[\left(d T / d \overline{T_{s}}\right) \Delta \overline{T_{s}}\right]_{\mathrm{Tr}}\right\}$. The nonlinear portion is computed by subtracting the linear variable change from the actual variable change \{e.g., $\left.\Delta T_{\operatorname{Tr}}-\left[\left(d T / d \overline{T_{s}}\right) \Delta \overline{T_{s}}\right]_{\mathrm{Tr}}\right\}$. These changes are multiplied by the radiative kernels to generate the linear and nonlinear portions of the clearsky TOA flux anomalies with subsequent vertical integrations for temperature and water vapor. Globalmean values are obtained by spatial averaging over the entire globe. Unlike the standard Gregory method, these processes produce the adjustments for each year of the simulations. Consequently, terms in parenthesis on the right-hand side of Eq. (2) are divided into climate 
responses associated with radiative feedbacks $\left(\mathrm{FB}^{0}\right)$ and rapid adjustment processes $\left(\mathrm{ADJ}^{0}\right)$, as follows:

$$
\mathrm{DIR}^{0}=\Delta R^{0}-\left(\mathrm{FB}_{\mathrm{Tr}}^{0}+\mathrm{FB}_{\mathrm{St}}^{0}+\mathrm{ADJ}_{\mathrm{Tr}}^{0}+\mathrm{ADJ}_{\mathrm{St}}^{0}\right) .
$$

The total-sky radiative flux imbalance at the TOA is decomposed, including the terms related to cloud changes $\Delta R_{\operatorname{Tr}, C}$ and residual $\varepsilon$ (difference between model-produced and radiative kernel-computed TOA total-sky radiative flux imbalance):

$$
\begin{aligned}
\Delta R= & \Delta R_{\mathrm{Tr}, T}+\Delta R_{\mathrm{Tr}, \mathrm{WV}}+\Delta R_{\mathrm{Tr}, a} \\
& +\Delta R_{\mathrm{Tr}, C}+\Delta R_{\mathrm{St}, T}+\Delta R_{\mathrm{St}, \mathrm{WV}}+\mathrm{DIR}+\varepsilon \\
\Delta R_{\mathrm{Tr}, C}= & \Delta \mathrm{CRE}+\left(K_{\mathrm{Tr}, T}^{0}-K_{\mathrm{Tr}, T}\right) \Delta T_{\mathrm{Tr}} \\
& +\left(K_{\mathrm{Tr}, \mathrm{WV}}^{0}-K_{\mathrm{Tr}, \mathrm{WV}}\right) \Delta \mathrm{WV}_{\mathrm{Tr}} \\
& +\left(K_{\mathrm{Tr}, a}^{0}-K_{\mathrm{Tr}, a}\right) \Delta a_{\mathrm{Tr}}+\left(\mathrm{DIR}^{0}-\mathrm{DIR}\right) .
\end{aligned}
$$

The radiative flux perturbations are attributed to feedback processes, rapid adjustments, and direct forcing in the same way as in the clear-sky case, except for the use of total-sky radiative kernels $(K s)$. The portion of changes proportional to global-mean surface temperature change is multiplied by total-sky radiative kernels to produce radiative flux changes associated with feedback processes. Consequently, the nonfeedback portion is regarded as a rapid adjustment. Because of the nonlinearity, radiative flux perturbations due to cloud changes are estimated from changes in CRE with a correction for the cloud masking effect and with an assumption that direct forcing in the total sky (DIR) is proportional to that for the clear sky $\left(\mathrm{DIR}^{0}\right)$ (Soden et al. 2004, 2008). An alternative technique, not used in this work, was proposed by Zelinka et al. (2012), in which cloud radiative kernels are used to quantify TOA radiative flux perturbations due to cloud changes in the case that cloud fraction anomalies diagnosed by the ISCCP simulator (Klein and Jakob 1999) are available (e.g., Forster et al. 2013; Zelinka et al. 2013).

This methodology is applied to a transient climate change scenario of phase 5 of the Coupled Model Intercomparison Project (CMIP5; Taylor et al. 2012). Figure 1 illustrates the results of the methodology of isolating radiative feedbacks, rapid radiative adjustments, and direct radiative forcing for the abrupt $4 \times$ $\mathrm{CO}_{2}$ experiment, in which the concentration of atmospheric carbon dioxide is quadrupled instantaneously relative to a preindustrial level and then held constant for $150 \mathrm{yr}$ ( $140 \mathrm{yr}$ for IPSL-CM5A-MR). Left and right panels represent clear sky and total sky, respectively. Each line represents multimodel ensemble mean with a single vertical error bar at the end of each time series denoting the time-averaged intermodel spread of \pm 1 standard deviation (Table S1 in the supplementary material lists climate models analyzed in this study). Radiative flux imbalances at the TOA (Fig. 1a) are decomposed into three components: 1) radiative flux perturbations arising from changes in feedback variables that develop in response to the resulting surface warming (Fig. 1b), 2) rapid radiative adjustments (Fig. 1c), and 3) direct forcing (Fig. 1d). The feedback radiative fluxes (radiative adjustments) of each variable are presented for the troposphere and stratosphere separately in Fig. 1b (Fig. 1c). A positive adjustment means that the total forcing is larger than the direct forcing (i.e., difference between the model-simulated radiative imbalance and the sum of feedbacks and adjustments). The unit of climate response associated with radiative feedbacks is in $\mathrm{W} \mathrm{m}^{-2}$, while the unit of radiative feedbacks is in $\mathrm{W} \mathrm{m}^{-2} \mathrm{~K}^{-1}$. In the case that the global-mean surface temperature changes are identical among models, the climate feedback can be directly related to the climate response.

Changes in the multimodel average temperature and water vapor in response to surface warming exert larger radiative flux perturbations than changes in surface albedo and clouds do. In contrast, stratospheric feedbacks exert minimal radiative influences. Since the stratospheric changes are assumed to be uncorrelated to global-mean surface temperature change, the radiative flux perturbations associated with the changes in temperature and water vapor above the dynamic tropopause can be regarded as stratospheric adjustments. While the rapid stratospheric temperature adjustment induces the multimodel mean TOA radiative flux perturbation of $\sim 1.8 \mathrm{~W} \mathrm{~m}^{-2}$, tropospheric adjustments do not exert comparable influences on the TOA radiative budget, even for clouds, because of multimodel averaging of opposing signs. Vertical error bars in Fig. 1d indicate that there is some spread among models in the direct radiative impact of an abrupt $\mathrm{CO}_{2}$ quadrupling. The jump in the direct forcings and the clear-sky TOA radiative flux imbalance around year 140 is a result of a single model (IPSL-CM5A-MR).

Figure $1 \mathrm{~d}$ also indicates that total-sky direct forcing is smaller than the clear-sky direct forcing. This is because clouds reduce the radiative impact of the $\mathrm{CO}_{2}$ forcing (e.g., Soden et al. 2008), resulting in a smaller intermodel spread in total-sky direct forcing. The residual $\varepsilon$ presented in Fig. 1e is computed by differencing TOA totalsky radiative flux imbalance produced by each model with that computed from the radiative kernels (i.e., the sum of total-sky radiative flux perturbations arising from the direct forcing, feedback processes, and rapid adjustments). The multimodel average of the residual is $\sim 0.1 \mathrm{~W} \mathrm{~m}^{-2}$ and provides an estimate of the level of 
Clear-sky
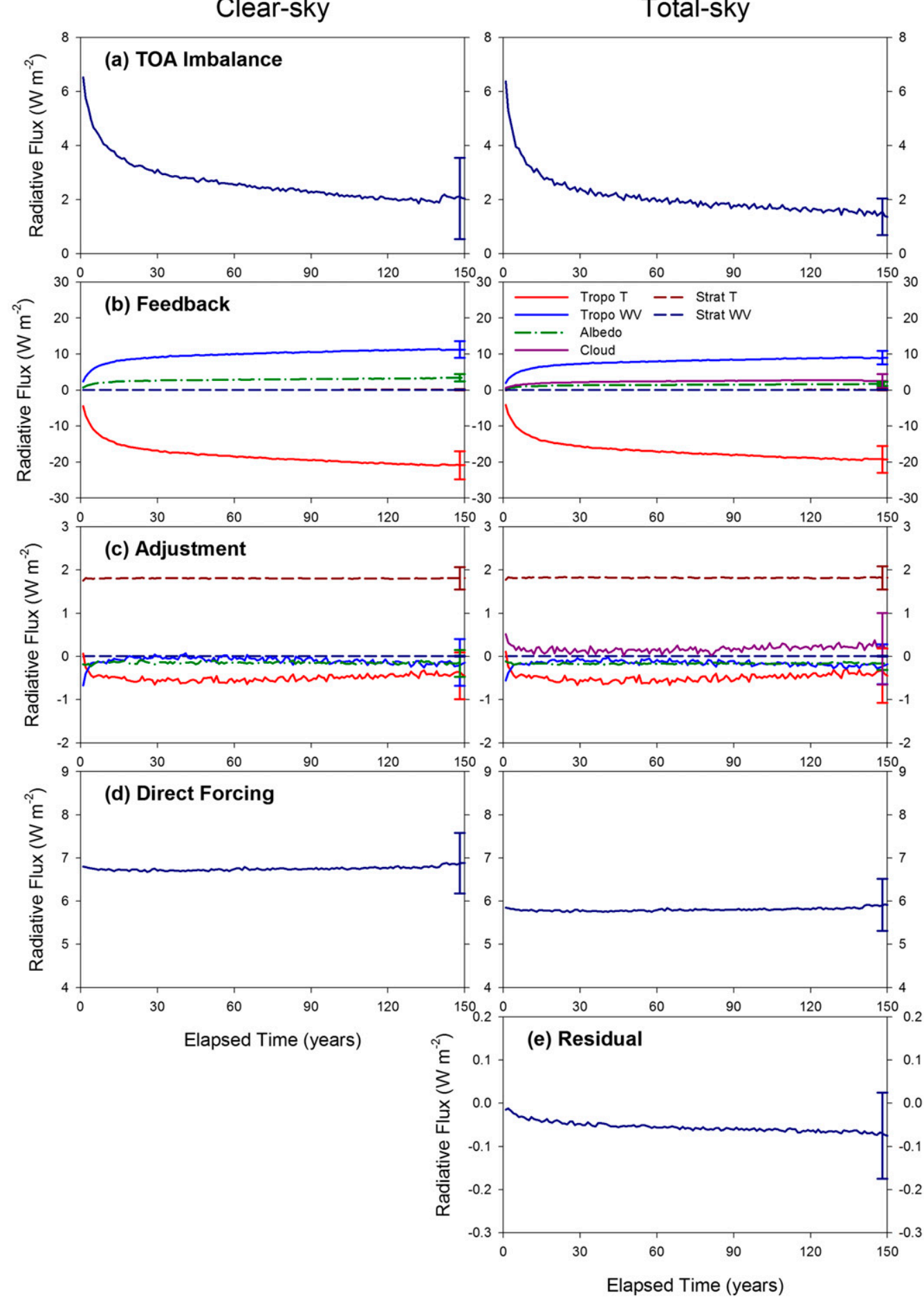

FIG. 1. Decompositions of multimodel mean global- and annual-average (a) TOA radiative flux imbalance into the response of (b) feedback variables to the surface warming induced by a $\mathrm{CO}_{2}$ quadrupling, (c) the rapid radiative adjustments to the imposed forcing, and (d) the direct radiative forcing from the $\mathrm{CO}_{2}$ quadrupling for (left) clear sky and (right) total sky over the 150 -yr period of the CMIP5 abrupt $4 \times \mathrm{CO}_{2}$ experiment. (e) Residuals in the decomposition of total-sky radiative flux imbalance. Lines represent multimodel ensemble mean. A single vertical error bar at the end of each time series denotes the time-averaged intermodel spread ( \pm 1 std dev). The ranges on the vertical axes are different. 
uncertainty in our determination of radiative feedbacks and radiative forcing. This may arise from uncertainties in the estimate of the total-sky direct forcing from the clear-sky direct forcing following Soden et al. (2008) or other possible sources of error, which are discussed in section $2 \mathrm{c}$.

\section{b. Comparison with the Gregory method}

The sums of direct forcing and rapid radiative adjustments are compared to the total forcing obtained from the Gregory method. For transient climate change experiments of an instantaneous $\mathrm{CO}_{2}$ increase, Gregory et al. (2004) introduced a linear regression method based on the energy balance of climate system, which enables one to efficiently estimate climate feedback parameter (i.e., slope of the linear regression fit), as well as an independent measure of radiative forcing (i.e., intercept of the linear regression fit). Because globalmean surface temperature change is zero at the beginning of the simulation, the intercept reflects the sum of direct forcing and the rapid stratospheric and tropospheric radiative adjustments (Gregory et al. 2004; Gregory and Webb 2008; Andrews and Forster 2008; Colman and McAvaney 2011; Andrews et al. 2012; Webb et al. 2013).

Figure 2 shows a scatterplot of total forcing (direct + adjustment) between the Gregory method and the combined radiative kernel-regression method. Each circle represents an individual model. In the case of the combined radiative kernel-regression method, annual values of total forcing are averaged over the 150-yr period in order to reduce subdecadal scale variability (e.g., Chung et al. 2012). Both methods produce total forcing values ranging from 5 to $9 \mathrm{~W} \mathrm{~m}^{-2}$. The root-meansquare error (rmse) of $0.41 \mathrm{~W} \mathrm{~m}^{-2}$ highlights the level of consistency between the radiative kernel-derived total forcing and that obtained from the Gregory method.

\section{c. Uncertainty in the radiative kernel methodology}

Because there is no explicit information on the clear-sky direct forcing provided from modeling groups, the clear-sky direct forcing is computed as the difference between model-produced clear-sky TOA net radiative flux imbalance and the sum of clear-sky radiative flux perturbations arising from changes in climate variables diagnosed with radiative kernels. As a result, our clear-sky direct forcing computation assumes that uncertainties in the radiative kernel methodology are negligible. In this section, we briefly summarize known sources of uncertainties in the kernel methodology.

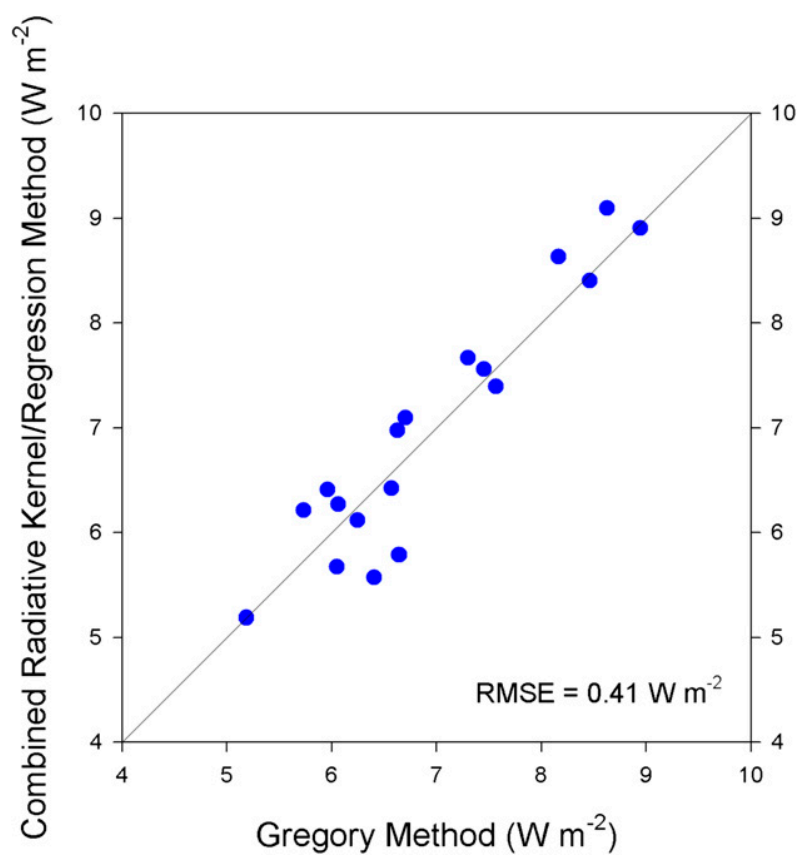

FIG. 2. Scatterplot of the sum of the combined radiative kernel/ regression-derived global-average direct radiative forcing and rapid radiative adjustments against the global-average total forcing estimated using the Gregory method for the CMIP5 abrupt $4 \times$ $\mathrm{CO}_{2}$ scenario for each model. The one-to-one line is shown for reference.

The construction of radiative kernels requires an unperturbed base climate and a radiative transfer model; therefore, uncertainties in both the base climate and radiative transfer algorithms can result in differences between feedbacks computed from different radiative kernels. Soden et al. (2008) compared feedbacks from three different sets of radiative kernels and found uncertainties to be on the order of $10 \%$ or less. Similar differences were obtained more recently by Vial et al. (2013) and Huang et al. (2014).

In addition, it is possible that changes between the two climate states being considered are large enough to introduce nonlinear response in the radiative fluxes (e.g., Jonko et al. 2012; Block and Mauritsen 2013; Vial et al. 2013). For example, Jonko et al. (2012) estimated the uncertainty in feedback parameter for clear-sky conditions for three successive $\mathrm{CO}_{2}$ doublings by comparing the feedback parameter computed based on $1 \times \mathrm{CO}_{2}$ radiative kernels with that derived from model fluxes. They found that the normalized difference between the feedback parameters increases from $9 \%$ for $(2 \times$ $\left.\mathrm{CO}_{2}\right)-\left(1 \times \mathrm{CO}_{2}\right)$ to $41 \%$ for $\left(4 \times \mathrm{CO}_{2}\right)-\left(2 \times \mathrm{CO}_{2}\right)$ and $49 \%$ for $\left(8 \times \mathrm{CO}_{2}\right)-\left(4 \times \mathrm{CO}_{2}\right)$. Vial et al. (2013) and Block and Mauritsen (2013) also argue that the use of $1 \times \mathrm{CO}_{2}$ radiative kernels can contribute to errors in the estimation of climate feedbacks and rapid 


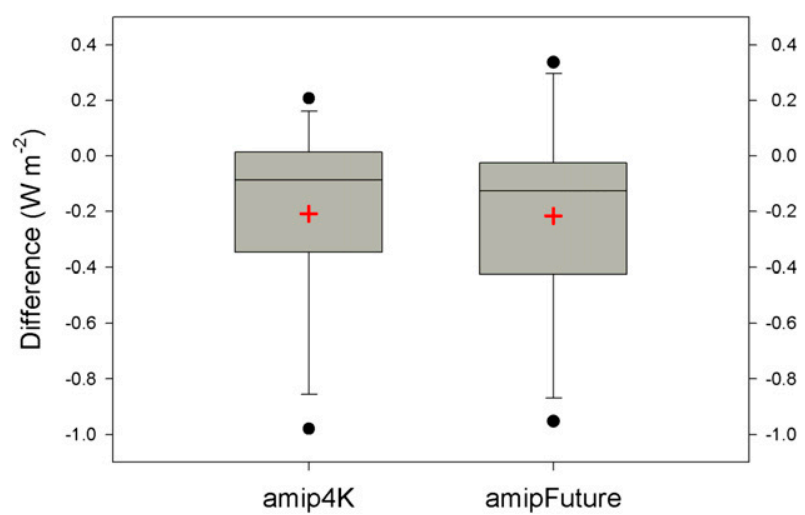

FIG. 3. Box-and-whisker plots of the difference between modelproduced global-mean clear-sky TOA net radiative flux imbalance and the sum of clear-sky radiative flux perturbations arising from changes in climate variables diagnosed with radiative kernels for the CMIP5 amip4K and amipFuture experiments. The line and red crosshair within the box represent the median and mean values, respectively. Outlier models are marked with closed dots.

adjustments for an abrupt $\mathrm{CO}_{2}$ quadrupling because of relatively large changes in the global-mean surface temperature (up to $7 \mathrm{~K}$ for some models at the end of the abrupt $4 \times \mathrm{CO}_{2}$ experiment).

Uncertainties can also occur because of differences between a model's native radiative transfer model and that used to create the kernel. To quantify the potential impact of this, we examine the differences in clear-sky direct forcing arising from the differences in radiative transfer algorithms using the CMIP5 atmospheric-only experiments over the period 1979-2008 (i.e., AMIP vs amip4K/amipFuture). Because TOA radiative flux perturbations relative to the base climate (AMIP experiment) result from SST changes only (i.e., no forcing agents), the right-hand side of Eq. (2) should be zero in the absence of forcing agents. In other words, a nonzero value implies an error due to differences in the radiative transfer algorithms. It is noted that nonzero values might also be produced, as the AMIP experiments allow the land surface to vary. Figure 3 displays box-andwhisker plots derived from nine climate models, which have the necessary output available for both the amip4K and amipFuture experiments. The estimated residuals (that excludes errors related to clouds) are within $\sim 0.4 \mathrm{~W} \mathrm{~m}^{-2}$ for most of the models, which is $\sim 5 \%$ of the mean radiative forcing for $4 \times \mathrm{CO}_{2}$. The median (line within the box) and mean (red crosshair within the box) values are around -0.1 and $-0.2 \mathrm{~W} \mathrm{~m}^{-2}$, respectively. Consistent with previous studies, the differences in radiative transfer algorithms between radiative kernels and models result in errors in the computation of radiative fluxes that are small compared to the imposed forcing and intermodel spread in feedback responses.

\section{Results}

In this section, radiative kernel-derived direct forcings, rapid adjustments, and feedbacks are compared between climate models to diagnose the primary causes of intermodel differences in the effective climate sensitivity (i.e., transient response of the climate system to a doubling of the atmospheric $\mathrm{CO}_{2}$ concentration), corresponding to a quadrupling of $\mathrm{CO}_{2}$. In addition, the regional patterns of multimodel ensemble means are analyzed.

\section{a. Global mean}

Since the radiative imbalance at the TOA is approximately equal to the ocean heat uptake, the radiative imbalance is referred to as heat uptake. The heat uptake at the TOA averaged over the years $131-140$ of the abrupt $4 \times \mathrm{CO}_{2}$ experiment is decomposed into direct radiative forcing, rapid radiative adjustments, and climate response related to feedback processes for each model (Fig. 4a). These decompositions might result in overestimated intermodel spread due to interannual/ decadal variations (e.g., Chung et al. 2010; Dalton and Shell 2013; Colman and Hanson 2013). As shown in Fig. 1, the direct radiative impact of an instantaneous $\mathrm{CO}_{2}$ quadrupling exhibits substantial intermodel spread, presumably due to biases of radiative transfer codes used in climate models compared to more accurate line-by-line codes (e.g., Collins et al. 2006; Forster et al. 2011), as well as differences in the base state. The intermodel spread in direct forcing of $\sim 3 \mathrm{~W} \mathrm{~m}^{-2}$ is quantitatively comparable to the spread in the radiative adjustments to that forcing. However, intermodel differences in these quantities are negatively correlated, resulting in an intermodel spread in total forcing of only $\sim 4 \mathrm{~W} \mathrm{~m}^{-2}$.

Transient response of the climate system to a $\mathrm{CO}_{2}$ quadrupling is estimated in terms of effective climate sensitivity (Murphy 1995; Senior and Mitchell 2000; Soden and Held 2006). The time-dependent effective climate sensitivity $\Delta T_{\text {eff }}$ corresponding to a quadrupling of $\mathrm{CO}_{2}$ can be estimated as follows:

$$
\Delta T_{\text {eff }}=\frac{\Delta R-\text { TOT }}{\mathrm{FB}_{\text {eff }}},
$$

where $\mathrm{FB}_{\text {eff }}$ and TOT (=DIR + ADJ) denote effective climate feedback parameter and total forcing, respectively. The effective climate feedback parameter $\mathrm{FB}_{\text {eff }}$ is obtained by summing individual feedback terms normalized by the temperature change (which would be different for different models). The effective climate sensitivity $\Delta T_{\text {eff }}$ for each model is estimated by inserting each model's values (i.e., $\Delta R$, DIR, $\mathrm{ADJ}$, and $\mathrm{FB}_{\text {eff }}$ ) into Eq. (6). Figure $4 \mathrm{~b}$ shows that the $4 \times \mathrm{CO}_{2}$ effective climate sensitivity ranges from 3 to $7 \mathrm{~K}$ for these models, 

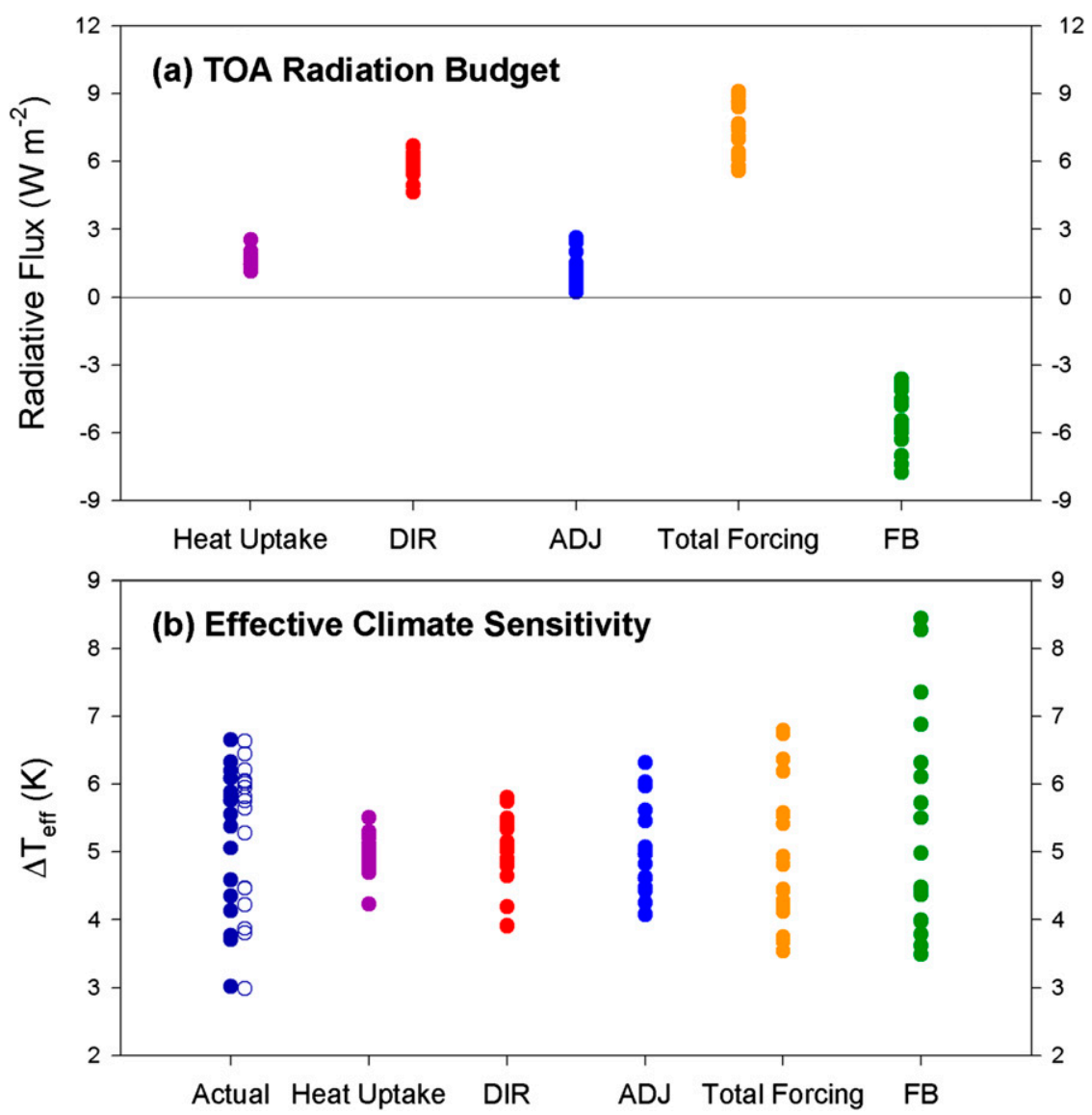

FIG. 4. Intermodel comparison of global-average TOA radiative budget and the corresponding $4 \times \mathrm{CO}_{2}$ effective climate sensitivity for the CMIP5 abrupt $4 \times \mathrm{CO}_{2}$ experiment. (a) Radiative flux imbalance at the TOA (i.e., heat uptake) is decomposed into the DIR, the $\mathrm{ADJ}$, and the response of feedback variables to the surface warming due to the $\mathrm{CO}_{2}$ quadrupling (FB). (b) Effective climate sensitivity is estimated by replacing each model's values by the corresponding multimodel mean, except for the labeled component in Eq. (6), in order to examine the primary causes of intermodel spread in the effective climate sensitivity (i.e., closed circles in the left column). These values are from the years 131-140 of the experiment. In (b), "actual" denotes the effective climate sensitivity for each model estimated by inserting each model's values (i.e., $\Delta R$, DIR, ADJ, and $\mathrm{FB}_{\text {eff }}$ ) into Eq. (6), and open circles indicate the difference in global, annual surface temperature between the years 131 and 140 and the control state. In (a) and (b), total forcing denotes the sum of direct radiative forcing and rapid radiative adjustments.

which are similar to the difference in global, annual surface temperature between the years 131-140 and the control state (open circles).

To examine contributions of each term to the intermodel spread in effective climate sensitivity, the intermodel range of effective climate sensitivity is computed using the multimodel mean values for all terms except one. For example, if heat uptake $\Delta R$ were the only term that varies in Eq. (6), the intermodel spread in effective climate sensitivity would decrease from $\sim 4$ to $\sim 1.5 \mathrm{~K}$. Similarly, if the radiative feedbacks $\mathrm{FB}_{\text {eff }}$ and heat uptake $\Delta R$ were consistent across models, the spread in effective climate sensitivity would still be close to its present value as a result of differences in the total radiative forcing (DIR + ADJ). Figure $4 \mathrm{~b}$ shows that both direct forcing and radiative adjustments contribute roughly equally to the spread in effective climate sensitivity. On the other hand, if models exhibited consistent radiative forcings and heat uptake, the spread in climate sensitivity would increase to $\sim 5.5 \mathrm{~K}$. These results demonstrate that uncertainties in the tropospheric feedbacks exert relatively larger contributions to the intermodel differences in climate sensitivity compared to heat uptake and forcings but that important correlations exist between feedback and forcings, which act to reduce the intermodel spread (Forster et al. 2013; Ringer et al. 2014). 

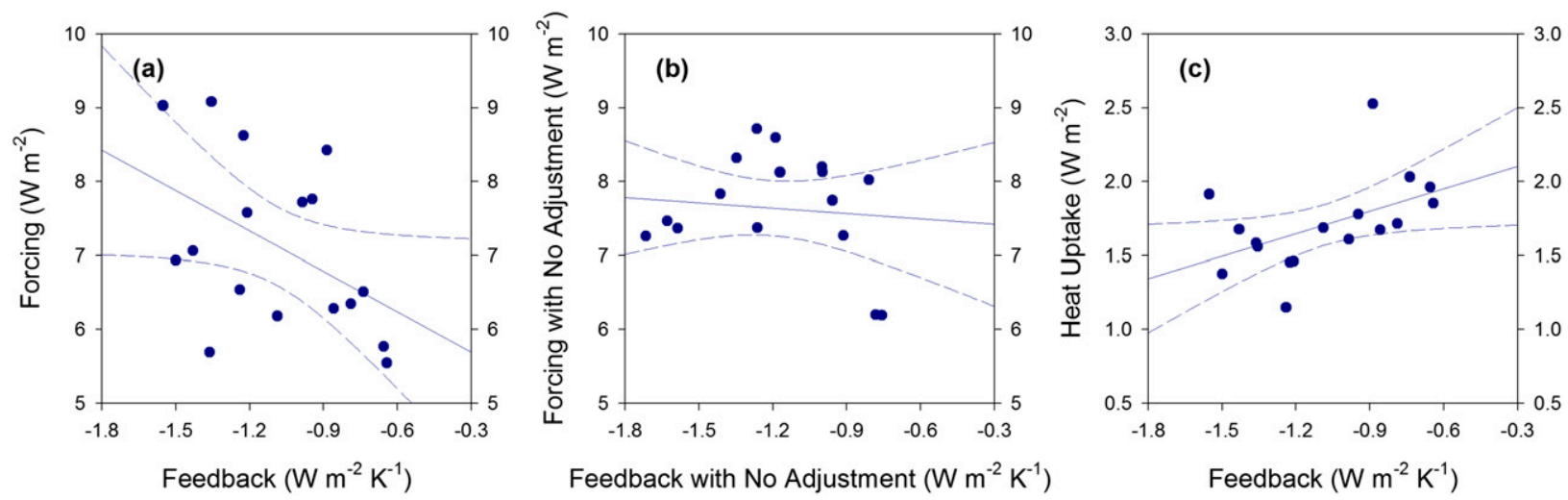

FIG. 5. Scatterplots of global-average (a) total forcing and (c) heat uptake over the years 131-140 of the simulations against globalaverage feedbacks for the CMIP5 abrupt $4 \times \mathrm{CO}_{2}$ experiment. (b) As in (a), but tropospheric adjustment is presumed to act as a feedback rather than a forcing. Solid and dashed lines denote lines of best fit and $95 \%$ confidence intervals.

Figure 5 shows that total feedback parameters are negative, with a smaller (in magnitude) feedback parameter corresponding to a higher climate sensitivity. It is also shown that there is an anticorrelation (correlation coefficient $=-0.47$, significant at $90 \%$ level) between feedback and total forcing (Fig. 5a). This value is comparable to that (i.e., -0.41 ) reported in Andrews et al. (2012). Feedback and total forcing estimates in Vial et al. (2013) for a smaller subset of CMIP5 models are also negatively correlated (correlation coefficient $=-0.37$ ). We note, however, that this compensation is reduced substantially if tropospheric adjustments are neglected and assumed to act as a feedback rather than a direct adjustment to $\mathrm{CO}_{2}$ (Fig. 5b). Figure 5c also indicates that heat uptake is positively correlated to feedback (correlation coefficient $=0.49$, significant at $95 \%$ ); i.e., higher sensitivity models tend to have smaller radiative forcings and larger heat uptake. The positive correlation between feedback and heat uptake implies that higher sensitivity models also require longer integrations to equilibrate. As a result of both of these correlations, the resulting spread in $\Delta T_{\text {eff }}$ is reduced (refer to Fig. $4 \mathrm{~b}$ ).

The spread in each adjustment component is compared in Fig. 6a (i.e., closed symbols). Both stratospheric and tropospheric (including the surface) portions of the rapid adjustments show noticeable intermodel spread. While climate models differ in the sign of rapid radiative adjustments for most of the tropospheric components, a positive sign is consistently produced for the stratospheric portion of the rapid radiative adjustments. Cloud radiative adjustment exhibits substantial intermodel spread with a multimodel mean of $\sim 0.3 \mathrm{~W} \mathrm{~m}^{-2}$. However, this ensemble mean value is much smaller compared to previous studies in which cloud radiative adjustment is estimated by imposing climatological sea surface temperature and sea ice concentration to inhibit climate feedbacks (i.e., CMIP5 sstClim and sstClim $4 \times$ $\mathrm{CO}_{2}$ experiments) and, in contrast to previous studies, the adjustments are more uniformly distributed around zero with both positive and negative values. For example, multimodel mean values are $\sim 1.1 \mathrm{~W} \mathrm{~m}^{-2}$ for five models in Zelinka et al. (2013) and $0.8 \mathrm{~W} \mathrm{~m}^{-2}$ for 11 models in Vial et al. (2013). The blue line in Fig. 6a indicates that the intermodel range of cloud adjustment is comparable to that of Zelinka et al. (2013), but comparatively less spread is obtained for Vial et al. (2013) estimates [particularly if one outlier model with a negative adjustment in Vial et al. (2013) is excluded (Fig. 6a, red line)]. Given the differences in methodology between the studies, a systematic comparison would be required to fully understand the differences in the estimated cloud adjustments.

Rapid adjustments of lapse rate and water vapor are also both positive and negative depending on models, resulting in smaller multimodel means (lapse rate: $-0.42 \mathrm{~W} \mathrm{~m}^{-2}$; water vapor: $-0.13 \mathrm{~W} \mathrm{~m}^{-2}$ ). Compared to the lapse rate and water vapor adjustments, the combined Planck, lapse rate, and water vapor adjustments show reduced intermodel spread due to a tight coupling between the temperature and water vapor changes (e.g., Soden and Held 2006). Most of the models show negative values for the surface albedo adjustment. This is physically unreasonable because regions covered with sea ice or snow would become less reflective in response to $\mathrm{CO}_{2}$-induced surface warming. In the next section, we argue that this and substantial parts of other tropospheric adjustments are largely artifacts of the methodology used to isolate them from surface-coupled feedbacks.

In addition to potential biases arising from the dependence of radiative kernels on the control climate state (Jonko et al. 2012; Block and Mauritsen 2013), the 

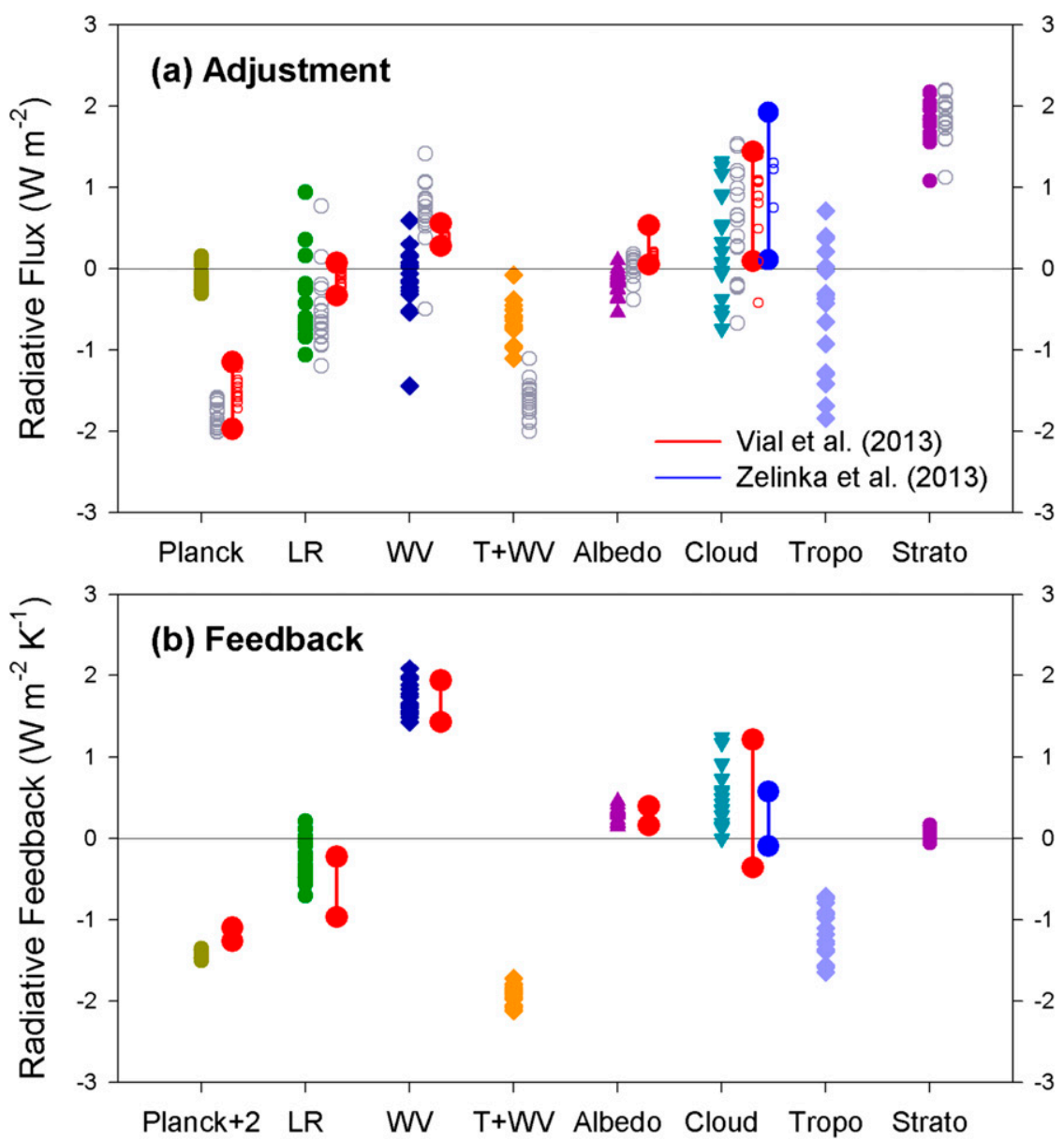

FIG. 6. Intermodel comparison of (a) rapid adjustment and (b) feedback for the CMIP5 abrupt $4 \times \mathrm{CO}_{2}$ experiment: Tropospheric Planck response, tropospheric lapse rate, tropospheric water vapor, surface albedo, clouds, and stratosphere. $T+\mathrm{WV}$ denotes the sum of Planck response, lapse rate, and water vapor. Tropo indicates the sum of Planck response, lapse rate, water vapor, surface albedo, and cloud. Planck +2 means that $2 \mathrm{~W} \mathrm{~m}^{-2} \mathrm{~K}^{-1}$ is added to Planck feedback for display purposes. In (a), open circles in gray represent the cases in which rapid adjustments are modified by adding the feedback from $0.5 \mathrm{~K}$ of global-mean surface warming. Also presented are intermodel ranges of adjustment and feedback estimates from Vial et al. (2013) and Zelinka et al. (2013). In (a), open circles in red and blue denote modelspecific results of adjustments from Vial et al. (2013) and Zelinka et al. (2013), respectively.

radiative adjustments estimated in this study might have biases because of nonlinear behaviors in the first few years subsequent to an instantaneous $\mathrm{CO}_{2}$ increase, as shown in previous studies (Andrews et al. 2012; Webb et al. 2013; Zelinka et al. 2013; Vial et al. 2013; Block and Mauritsen 2013). To avoid these issues, the rapid adjustments have alternatively been derived from atmosphereonly simulations in which sea surface temperature and sea ice concentration are fixed to climatological values. Since there is no restriction on land surface and sea ice covered areas, however, the rapid adjustments estimated from the atmosphere-only simulations could also be subject to biases.
For instance, the multimodel mean Planck adjustment estimate is $-1.51 \mathrm{~W} \mathrm{~m}^{-2}$ in Vial et al. (2013). On the other hand, our calculated Planck adjustment is clustered around $0 \mathrm{Wm}^{-2}$ in Fig. 6 a, implying that land surface warming (which is included in the Vial et al. (2013) adjustment calculations but not in ours) may cause apparent discrepancies in rapid adjustments between Vial et al. (2013) and this study. We examine this by adding the radiative flux perturbations resulting from each model-derived feedback with a global-mean surface warming of $0.5 \mathrm{~K}$ (typical of the warming induced by a quadrupling of $\mathrm{CO}_{2}$ in fixed SST experiments) to the corresponding adjustments (gray open circles in 


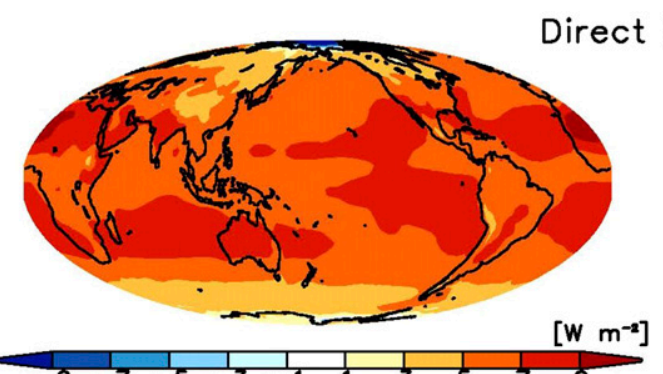

orcing
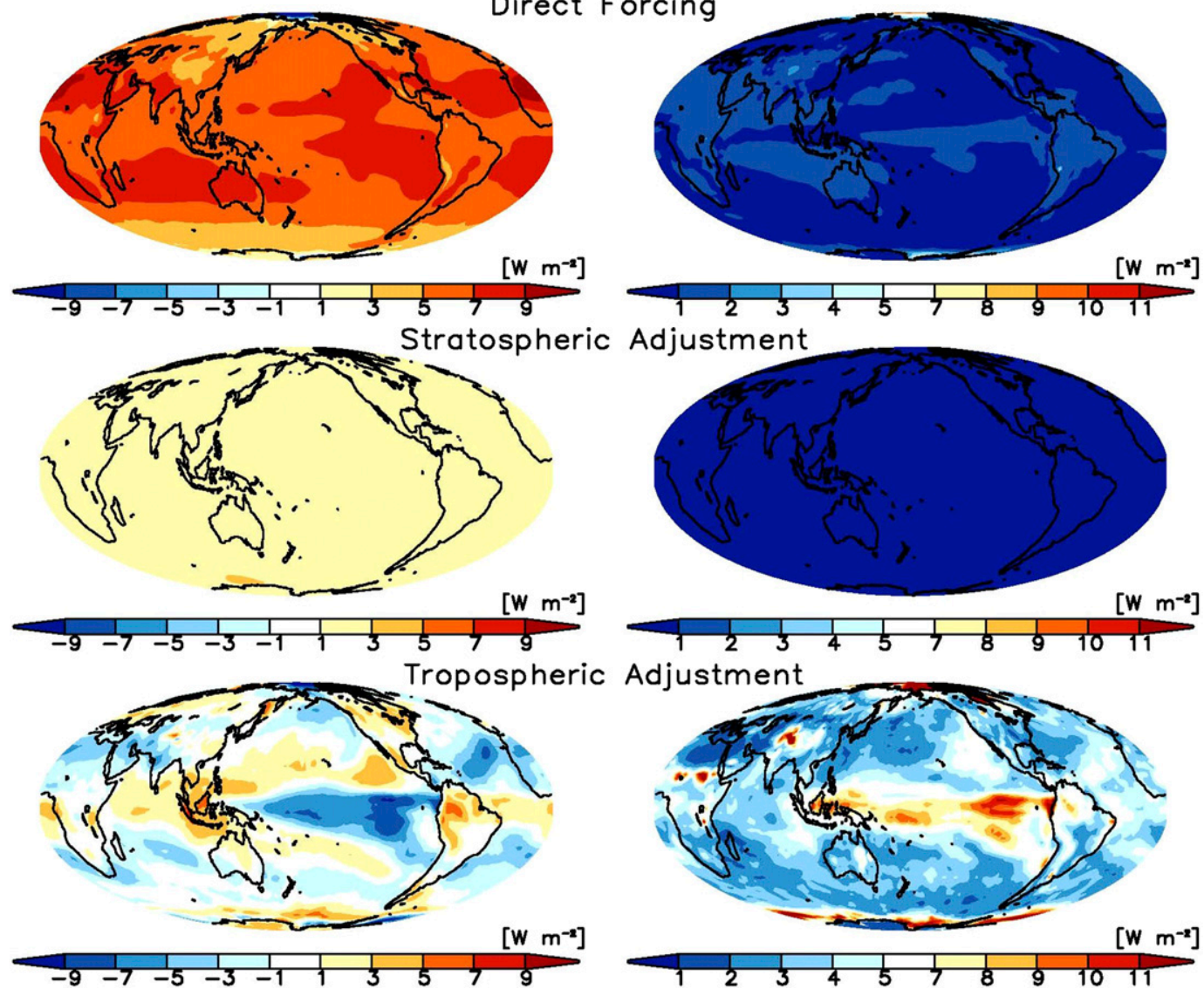

FIG. 7. Geographical distribution of direct radiative forcing, stratospheric adjustment, and tropospheric adjustment (unit: $\mathrm{W} \mathrm{m}^{-2}$ ) averaged over the whole $150 \mathrm{yr}$ of the simulations for the CMIP5 abrupt $4 \times \mathrm{CO}_{2}$ experiment: (left) multimodel mean and (right) intermodel spread ( \pm 1 std dev). (right) These distributions have a smaller range.

Fig. 6a). Specifically, the radiative flux perturbations (unit: $\mathrm{W} \mathrm{m}^{-2}$ ) are computed by multiplying the globalaverage feedback parameters (unit: $\mathrm{W} \mathrm{m}^{-2} \mathrm{~K}^{-1}$ ) by $0.5 \mathrm{~K}$. Interestingly, the modified Planck adjustment is in good agreement with the estimate in Vial et al. (2013). The discrepancy in cloud adjustment between this study and Vial et al. (2013) is also slightly reduced by accounting for global-mean surface warming in fixed SST experiments. The multimodel mean cloud adjustment increases from 0.29 to $0.54 \mathrm{~W} \mathrm{~m}^{-2}$ if the surface warming of $0.5 \mathrm{~K}$ is considered. Therefore, the discrepancy in tropospheric adjustments is at least partially attributable to small but nonnegligible global-mean surface warming in fixed SST experiments, which aliases a surface-driven feedback response into estimates of the adjustments.

Figure $6 \mathrm{~b}$ compares the strength of the individual feedbacks among models. Because of different units between Fig. 6a $\left(\mathrm{W} \mathrm{m}^{-2}\right)$ and Fig. 6b $\left(\mathrm{W} \mathrm{m}^{-2} \mathrm{~K}^{-1}\right)$, a direct comparison with adjustments is not possible. However, most feedback terms multiplied by the corresponding global-mean surface temperature change are much larger in the global, annual average than the adjustments (Fig. 1). It is noted that stratospheric feedbacks are virtually nonexistent in these models. The sign and intermodel spread of the tropospheric feedbacks for a $\mathrm{CO}_{2}$ quadrupling are generally consistent with estimates from the Intergovernmental Panel on Climate Change (IPCC) Fourth Assessment Report (AR4) based on the results of Soden and Held (2006), as well as estimates from Vial et al. (2013) for 11 models of the CMIP5. One exception is cloud feedback, in which the multimodel mean $\left(0.47 \mathrm{~W} \mathrm{~m}^{-2} \mathrm{~K}^{-1}\right)$ is smaller than the estimate $\left(\sim 0.69 \mathrm{~W} \mathrm{~m}^{-2} \mathrm{~K}^{-1}\right)$ of Soden and Held (2006), although an equivalent comparison is difficult because of the use of different models and as a result of the difference in experiment types. In contrast, the multimodel mean here is larger than estimates of Zelinka et al. (2013) and Vial et al. (2013), which are $0.30 \mathrm{~W} \mathrm{~m}^{-2} \mathrm{~K}^{-1}$ for five models and $0.27 \mathrm{~W} \mathrm{~m}^{-2} \mathrm{~K}^{-1}$ for 11 models, respectively. Note that Vial et al. (2013) 

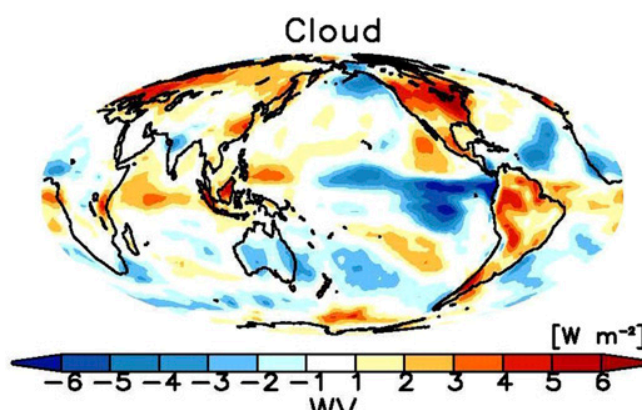

WV

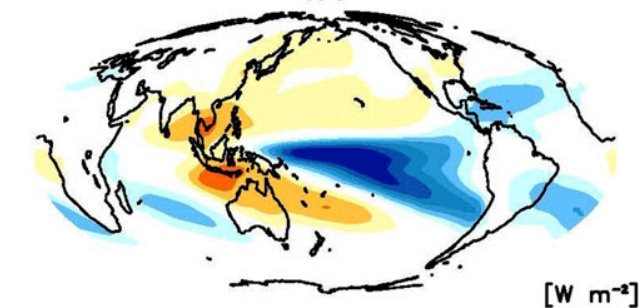

$\left[\mathrm{W} \mathrm{m}^{-2}\right]$
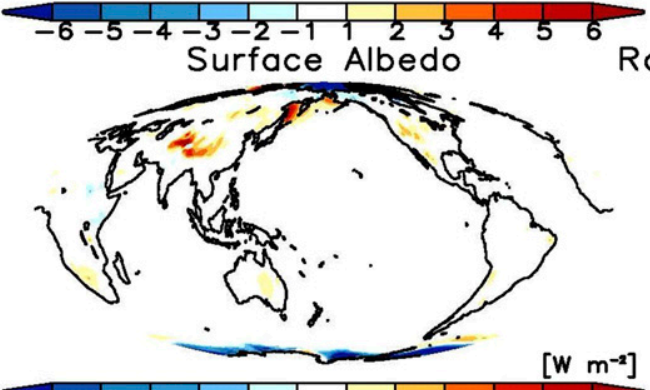

$\left[\mathrm{W} \mathrm{m}^{-\mathrm{x}}\right]$

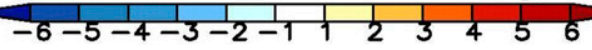

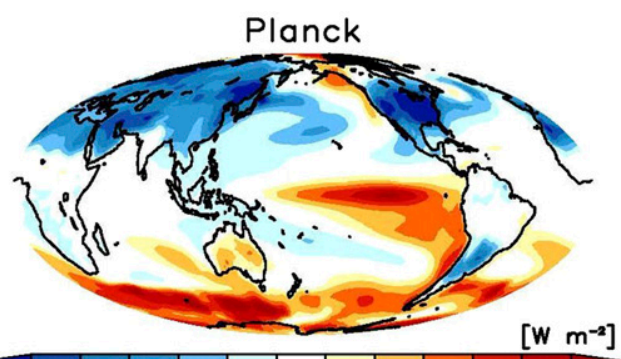

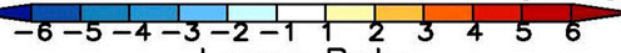
Lapse Rate
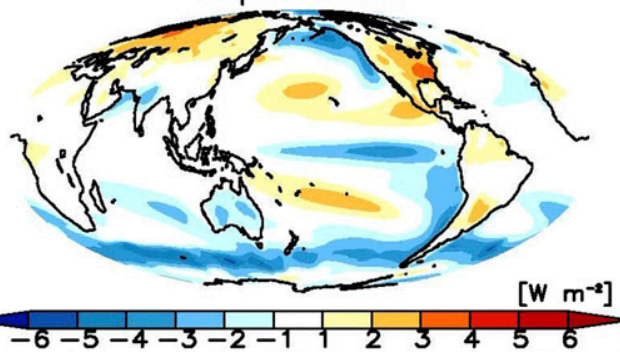

Ratio of Local to Global-Mean Warming

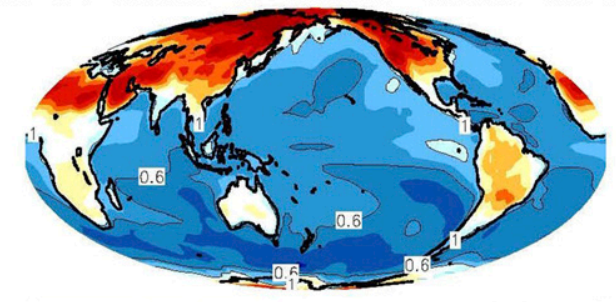

$0.20 .40 .60 .8 \frac{1}{1.21 .41 .61 .8} \quad \frac{1}{2} 2.22 .4$

FIG. 8. Geographical distribution of multimodel mean tropospheric adjustments (unit: $\mathrm{W} \mathrm{m}^{-2}$ ) averaged over the whole $150 \mathrm{yr}$ of the simulations for the CMIP5 abrupt $4 \times \mathrm{CO}_{2}$ experiment. Also displayed is the ratio of local to global-mean surface warming for the first year subsequent to an instantaneous $\mathrm{CO}_{2}$ quadrupling (bottom right).

quantified the strength of radiative feedbacks from the 30 -yr mean of the sstClim $4 \times \mathrm{CO}_{2}$ experiment and the 10 -yr mean of the abrupt $4 \times \mathrm{CO}_{2}$ experiment. Andrews et al. (2012) showed that cloud radiative effect evaluated feedback (defined as change in CRE normalized by global-mean surface temperature change) for the abrupt $4 \times \mathrm{CO}_{2}$ experiment shows significant intermodel spread among 15 models with a multimodel mean of $0.02 \mathrm{~W} \mathrm{~m}^{-2} \mathrm{~K}^{-1}$. Although quantification of cloud feedback is substantially sensitive to methodologies, these studies are consistent with each other in that cloud feedback is the main cause of the intermodel spread of climate feedbacks.

Because the Planck response (although it is not a feedback) is by definition linked to the surface-driven changes, not $\mathrm{CO}_{2}$, the radiative flux perturbations arising from these changes should be classified entirely as feedback processes. However, Fig. 6a shows that the Planck response does have nonzero adjustments. Therefore, the linear regression method used here has sources of error and uncertainty associated with fitting/sampling and aliasing by land temperature changes. This regression method does allow portions of the surface-driven response to be aliased into tropospheric adjustments because of spatial inhomogenieties in the initial rate of surface warming and strength of radiative feedbacks. To better understand the errors in the global adjustment calculations, the next section examines regional patterns of the adjustments.

\section{b. Regional patterns of forcings, adjustments, and feedbacks}

Spatial patterns of the multimodel mean and intermodel variability are displayed for the direct forcing, stratospheric adjustments, and tropospheric adjustments (Fig. 7). As expected, the direct forcing and stratospheric adjustments tend to be spatially homogeneous compared to the tropospheric adjustments, which are characterized by large regional variations of opposing signs and greater variability between models.

Given the substantial spatial and intermodel variability of tropospheric adjustments, spatial distributions 


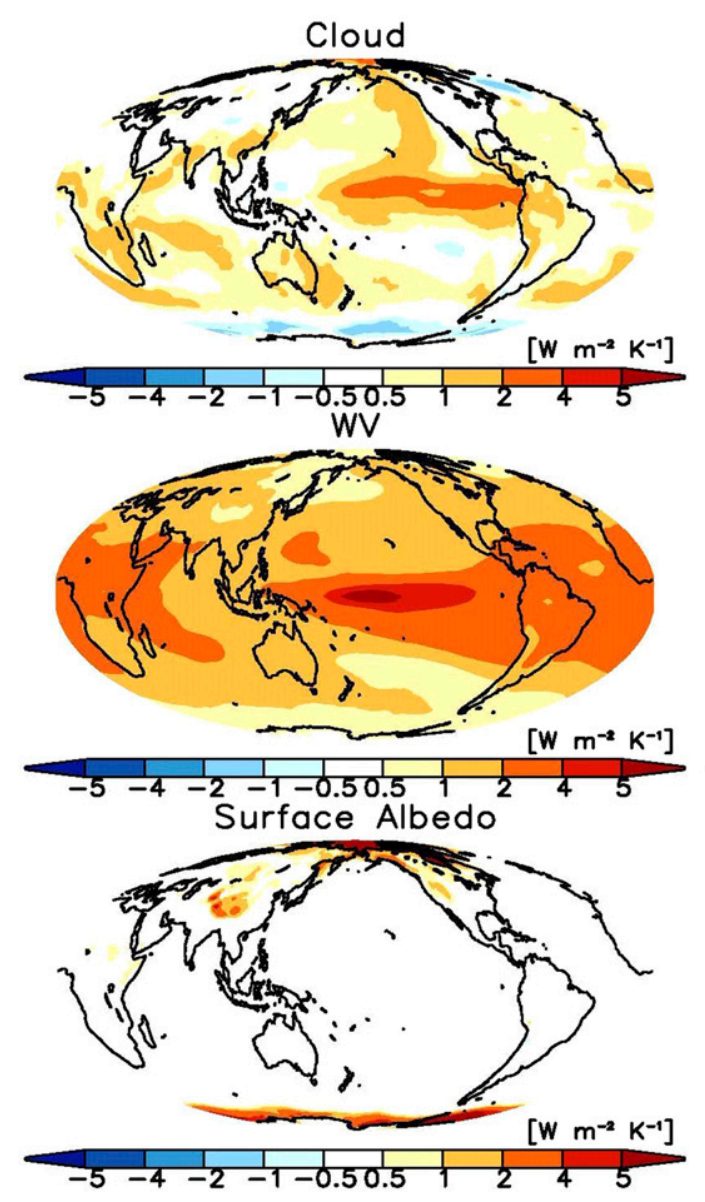

are further examined by decomposing the tropospheric adjustments into those from each component (Fig. 8). The Planck adjustment exhibits the largest spatial variations, with large negative values over the continents in the Northern Hemisphere, positive over the Southern Ocean and equatorial/southeastern Pacific, and nearly neutral over most of the tropics. This spatial variability of Planck adjustment reflects inhomogeneity in the initial rate of surface warming (lower-right panel). Regions that warm more rapidly (e.g., Northern Hemisphere continents) exhibit a large negative Planck adjustment, whereas regions that warm more slowly (e.g., Southern Ocean) have a positive adjustment. Similar adjustments are seen for clouds over many Northern Hemisphere land regions. Although some processes (e.g., upper-tropospheric humidity changes) are not closely coupled to the surface (e.g., Chung et al. 2011), the spatial similarity of the lapse rate, water vapor, and cloud adjustments to the Planck adjustment over the tropical Pacific further suggests that these changes are likely coupled to the surface (i.e., feedbacks), rather than a direct response to increased $\mathrm{CO}_{2}$ (i.e., adjustments).

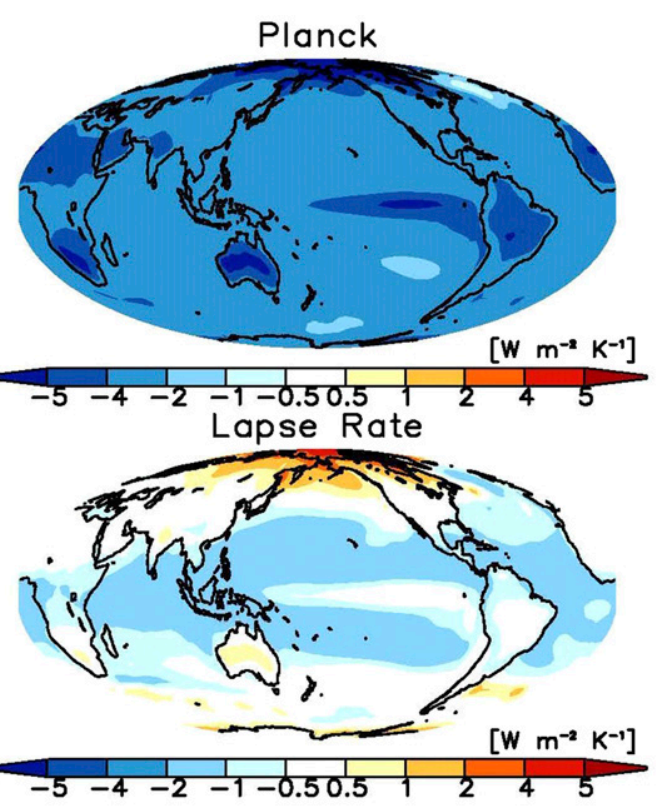

FIG. 9. Geographical distribution of multimodel mean tropospheric feedbacks (unit: $\mathrm{W} \mathrm{m}^{-2} \mathrm{~K}^{-1}$ ) for the CMIP5 abrupt $4 \times \mathrm{CO}_{2}$ experiment.

Even more striking is the spatial similarity between the patterns of the adjustment and the corresponding feedback (Fig. 9). For each feedback-adjustment pair, the spatial pattern of the adjustment tends to oppose the feedback. Some of the spatial pattern of the adjustment is induced by the methodology and can be explained in terms of a linear, but spatially varying, feedback in conjunction with spatially inhomogeneous warming. Consider the continents in the Northern Hemisphere, which exhibit greater initial surface warming than the global mean, resulting in a negative Planck adjustment. In contrast, compared to the global mean, the Southern Ocean shows less warming, consistent with a positive Planck adjustment. Since warming is spatially more uniform in the troposphere than at the surface, the initial rate of surface warming determines the spatial compensation between Planck and lapse rate adjustments as well as the spatial pattern of Planck feedback. The other regions have initial warming close to the global mean and thus tend to have generally weak, indistinct Planck and associated lapse rate adjustments. However, a strongly positive Planck adjustment is obtained over the equatorial Pacific Ocean, where the Planck feedback is 

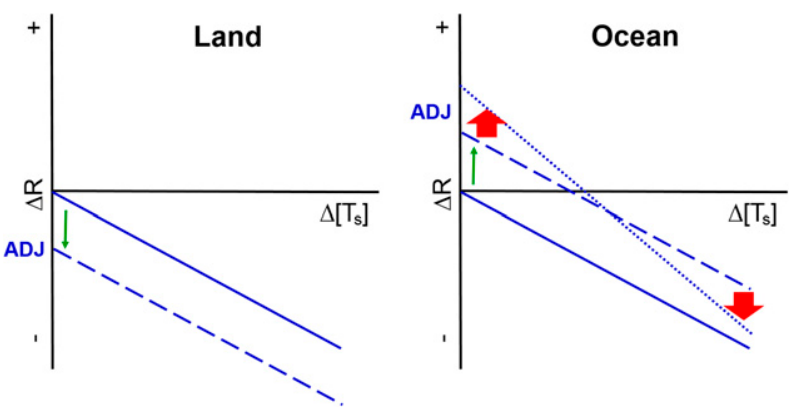

FIG. 10. A schematic illustrating an artificial compensation between feedback and adjustment for the Planck response as an example. The solid line in blue denotes changes in incoming TOA radiative flux $\Delta R$ arising from the Planck response to local surface warming as a function of global-mean surface temperature change $\Delta\left[T_{s}\right]$, with a slope of the line indicating the strength of Planck feedback, which should be negative. In a linear regression method, rapid adjustment is determined as the intercept at $\Delta\left[T_{s}\right]=0$. Because the small heat capacity of land results in the initial rate of surface warming greater than the global mean, the intercept shifts over land from zero to a negative value (refer to the green arrow and dashed line in blue). Conversely, over the ocean, a positive intercept is obtained as a result of comparatively slower initial warming. However, in the linear regression, an artificial compensation between the slope and the intercept may occur over some oceanic regions where temperature increase is enhanced afterward because of changes in atmospheric and oceanic circulations, resulting in a more negative regression slope and forcing the intercept to be more positive, as represented by the block arrows in red and dotted line in blue.

much stronger than surrounding areas. The stronger equatorial Pacific Planck feedback results in a larger (more negative) slope in our regression calculations, resulting in a more positive calculated $y$ intercept (adjustment).

Figure 10 provides a schematic illustration of this artificial compensation between feedback and adjustment for the Planck response as an example. The same explanation can be used to understand the relationship between the individual adjustments and feedbacks more broadly. Because this explanation assumes a linear feedback with no global average adjustment, this implies that some of the adjustment derived from our regression methodology may be changes that are coupled to the surface warming rather than direct responses to $\mathrm{CO}_{2}$. This interpretation is also consistent with other recent studies (e.g., Armour et al. 2013; Feldl and Roe 2013) in which the global climate feedbacks are related to the spatial pattern of local climate feedbacks and the spatial pattern of surface warming at any given time.

Figure 6 indicates that clouds exhibit the largest uncertainties in both radiative feedback and rapid radiative adjustments given the tight coupling of atmospheric temperature and water vapor. Furthermore, significant regional variability is identified for both cloud feedbacks and adjustments (Figs. 8 and 9). To quantify the regional

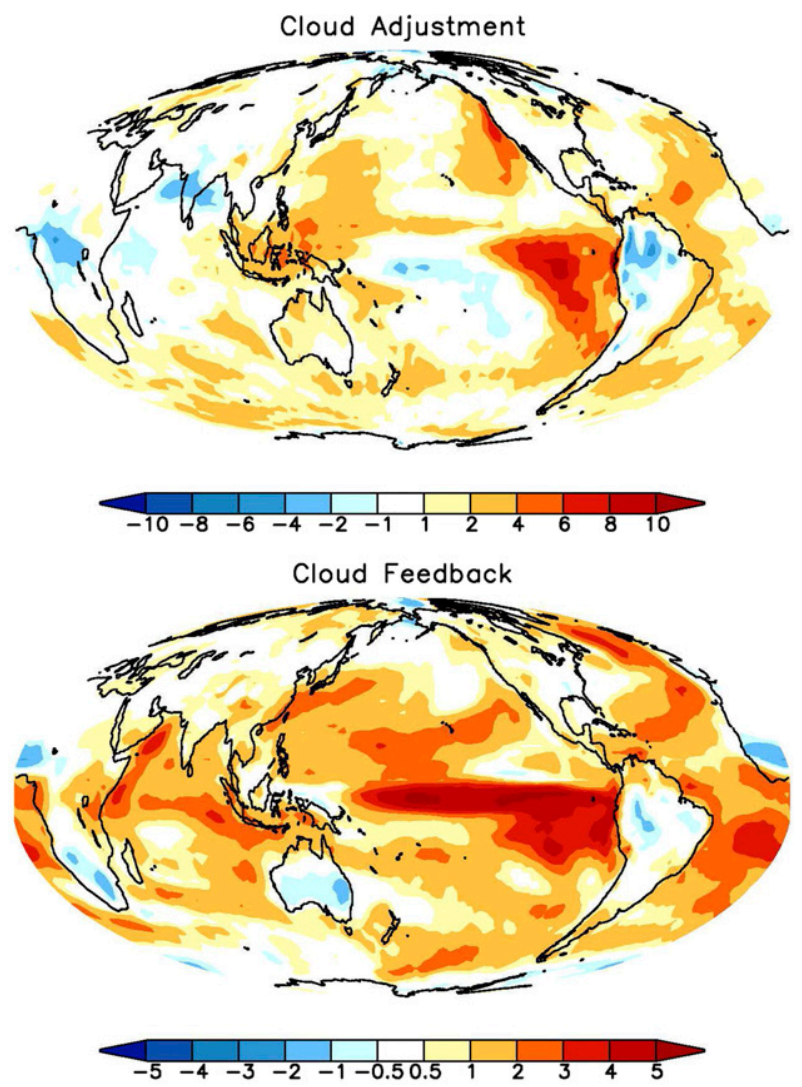

FIG. 11. Spatial pattern of the intermodel regression of the local values against the global mean: (top) cloud adjustment and (bottom) cloud feedback. The units are dimensionless, and the color scale for the adjustments is specifically twice that of the feedback.

contributions to the intermodel spread in the globalmean cloud feedback and adjustments, the intermodel regression of the local values of cloud feedback and adjustments are conducted against the corresponding global-mean values. Figure 11 highlights regions responsible for the intermodel spread in global mean. In the case of rapid adjustments, the subsidence regions over the southeastern and northeastern Pacific Ocean contribute the most to the intermodel spread in globalmean adjustments (e.g., Webb et al. 2013). Except for convectively active regions, land does not show large magnitudes of regression slope, implying that positive cloud adjustments over land are a robust feature across models (e.g., Zelinka et al. 2013; Vial et al. 2013; Block and Mauritsen 2013). The largest contributions to the intermodel spread in global-mean cloud feedback come from the equatorial Pacific. Considering that the local maxima of cloud feedback are located over the same region, intermodel differences in the location of intertropical convergence zones (e.g., Li and Xie 2014) are likely responsible for the spread. Large contributions are also identified over the large-scale subsidence regions in 


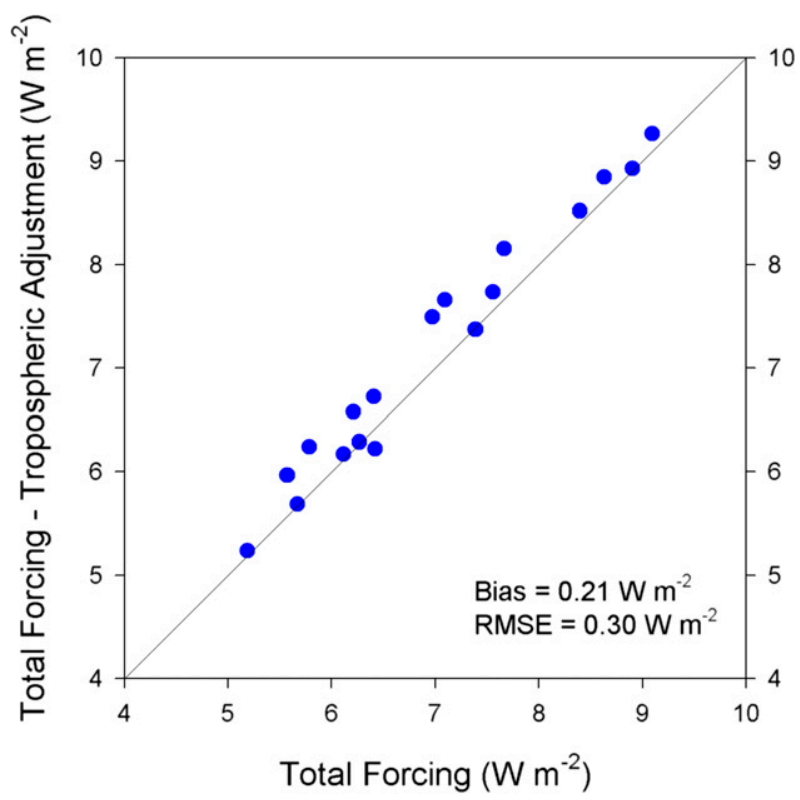

FIG. 12. Scatterplot of global-average total forcing minus the tropospheric adjustment against global-average total forcing averaged over the whole $150 \mathrm{yr}$ of the simulations for the CMIP5 abrupt $4 \times \mathrm{CO}_{2}$ scenario.

the tropical oceans (e.g., Bony and Dufresne 2005; Soden and Vecchi 2011; Webb et al. 2013; Vial et al. 2013).

\section{Potential application to other scenarios}

Realistic past or future scenarios accompany timedependent radiative forcing (e.g., Forster et al. 2013; Andrews 2014). Hence, the linear forcing-feedback framework cannot be used to accurately estimate adjusted forcing for realistic scenarios. Figures 1 and 6 , however, imply that the multimodel mean tropospheric adjustment tends to be small because of opposing signs among models in terms of the global average, unlike the stratospheric adjustment. Since the stratospheric changes can be regarded as an adjustment to imposed forcing agents (e.g., Hansen et al. 2005), for the multimodel mean, the total forcing can be approximated as the sum of direct radiative forcing and only the stratospheric adjustment. Moreover, the correlation between feedback and adjustment patterns suggests that some of the adjustment may be an artifact of the regression methodology and could be more appropriately interpreted as a surface-driven feedback.

Figure 12 examines the uncertainty that results in total forcing by neglecting the tropospheric adjustment. Neglecting the tropospheric portion causes a positive bias of $0.21 \mathrm{~W} \mathrm{~m}^{-2}$ and the rmse of $0.30 \mathrm{~W} \mathrm{~m}^{-2}$. Figure 13 compares the sum of each model's global-average radiative feedbacks and rapid adjustments (i.e., total change) with its feedback alone, demonstrating that many of the adjustments are likely to be feedbacks. Inclusion of rapid adjustments induces negative biases in the total change compared to the corresponding noncloud feedbacks, but the differences between the two are insignificant relative to the intermodel spread in feedbacks. For CMIP3 slab ocean models, Andrews and Forster (2008) showed that neglecting cloud adjustments leads to considerable uncertainty in quantification of cloud feedback. In addition, by analyzing five CMIP5 model outputs for the abrupt $4 \times \mathrm{CO}_{2}$ scenario, Zelinka et al. (2013) estimated a $\sim 50 \%$ increase in cloud feedback estimates if adjustments are included as feedback. Vial et al. (2013) also showed that the strength of cloud feedback averaged over 11 models increases by $33 \%$ if adjustments are included as feedback. In line with those previous results, Fig. 13d indicates that the inclusion of adjustments as feedback induces positive biases. However, the magnitude $(\sim 15 \%)$ is substantially smaller than the earlier estimates of Zelinka et al. (2013) and Vial et al. (2013). Differences in the number of analyzed models, ocean-atmosphere coupling, and methodology appear to cause this discrepancy. Further studies are required to fully resolve these issues.

How important is the separation of tropospheric adjustments for assessing effective climate sensitivity in relation to the climate change projection? To answer this, the $4 \times \mathrm{CO}_{2}$ effective climate sensitivity [Eq. (6)] is estimated with two sets of climate feedback parametertotal forcings pairs: in the first pair, the tropospheric adjustments are included with the forcing, while the second classifies all tropospheric adjustments as part of feedback. Figure 14 shows that bias and rmse between the two estimates are 0.04 and $0.21 \mathrm{~K}$, respectively, indicating that including the tropospheric adjustments as part of the tropospheric feedbacks causes minimal uncertainties in the assessment of transient climate response in terms of global mean.

Although uncertainties in the separation of rapid adjustments and feedback response cannot be ruled out, these results illustrate that the classification of the tropospheric responses as either a fast adjustment to the forcing or as a feedback related to the surface warming has little impact on the quantification of the global-average forcing, feedbacks, or climate sensitivity terms. The methodology outlined here can then also be applicable to timedependent forcing scenarios with minimal loss of accuracy.

\section{Summary}

In this study, we have applied a radiative kernel method (Soden et al. 2008; Shell et al. 2008) in conjunction with the 

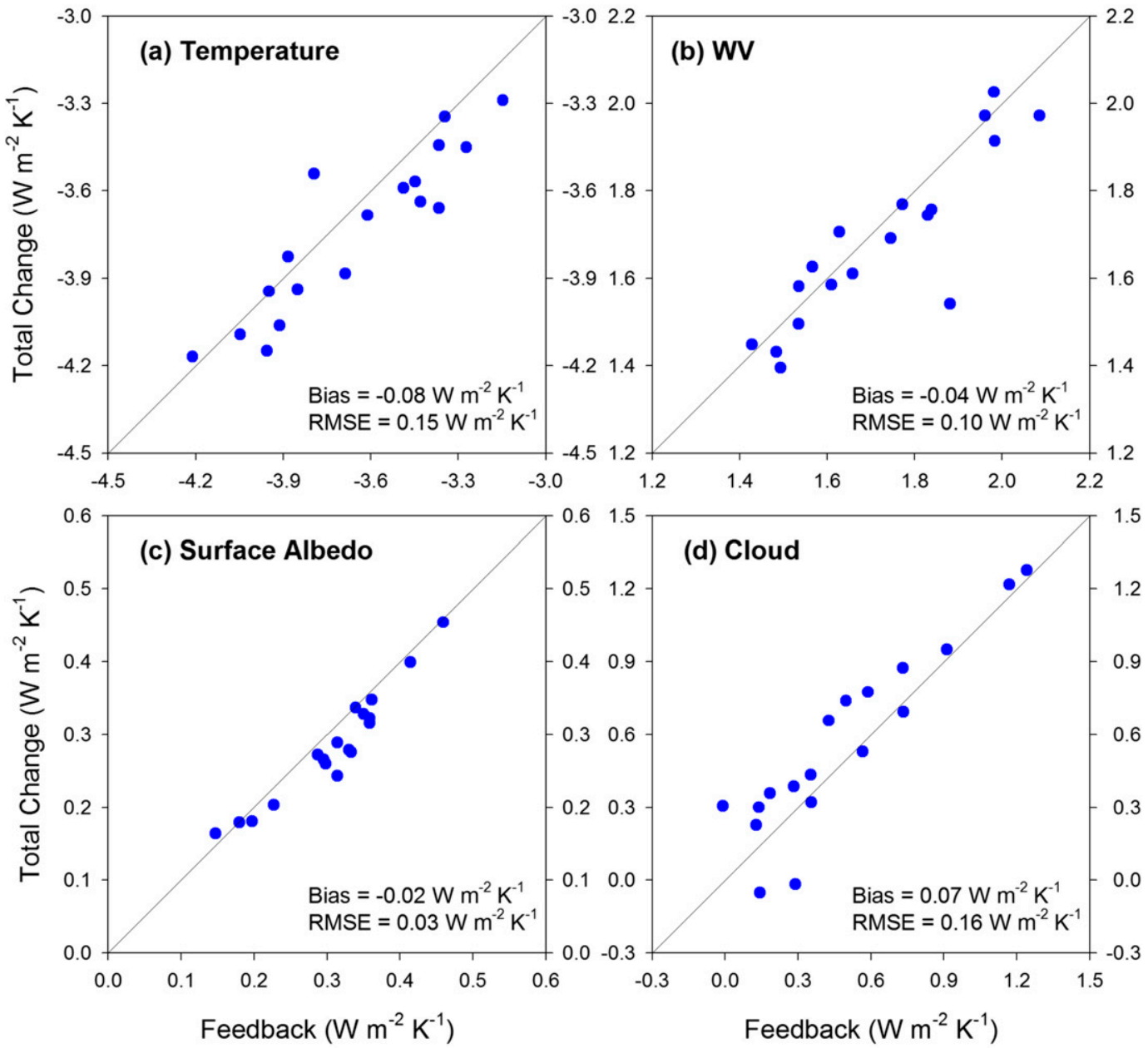

FIG. 13. Scatterplots of the sum of each model's global-average radiative feedbacks and rapid adjustments (i.e., total change) vs its feedback alone for the CMIP5 abrupt $4 \times \mathrm{CO}_{2}$ experiment. The one-to-one line is shown for reference.

linear forcing-feedback framework of Gregory et al. (2004) to decompose radiative flux anomalies at the TOA in an ensemble of coupled ocean-atmosphere models forced by an instantaneous $\mathrm{CO}_{2}$ quadrupling. The direct radiative forcing from a quadrupling of $\mathrm{CO}_{2}$ is separated from rapid radiative adjustments in the stratosphere and troposphere, as well as radiative feedbacks arising from the resulting surface warming. The total forcing, the sum of the direct radiative forcing and rapid radiative adjustments, was found to be consistent in strength and intermodel range with that determined using the Gregory method for the CMIP5 abrupt $4 \times \mathrm{CO}_{2}$ scenario.

In spite of the identical experimental design among climate models, analysis revealed a noticeable intermodel spread of $\sim 3 \mathrm{~W} \mathrm{~m}^{-2}$ in the direct radiative forcing from a quadrupling of $\mathrm{CO}_{2}$, implying that substantial uncertainties in projected climate change could result simply from intermodel discrepancy in the direct radiative forcing if there were no other compensating factors. The diagnosed intermodel spread is likely related to biases of radiative transfer codes included in climate models (e.g., Collins et al. 2006; Forster et al. 2011), inherent uncertainties arising in the methodology, and differences in the base states of the models. In spite of comparable spread in the rapid adjustments, intermodel spread only slightly increases from $\sim 3 \mathrm{~W} \mathrm{~m}^{-2}$ for direct forcing to $\sim 4 \mathrm{~W} \mathrm{~m}^{-2}$ for total forcing. As reported in previous studies, clouds are the primary cause for intermodel discrepancy in the tropospheric adjustment (e.g., Gregory and Webb 2008; Andrews and Forster 2008; Andrews et al. 2012; Zelinka et al. 2013; Vial et al. 2013), as well as for intermodel discrepancy in the radiative feedbacks (e.g., Bony et al. 2006; Soden and Held 2006; Andrews et al. 2012; Zelinka et al. 2013; Vial et al. 2013). However, in contrast to these previous studies, we obtained relatively 


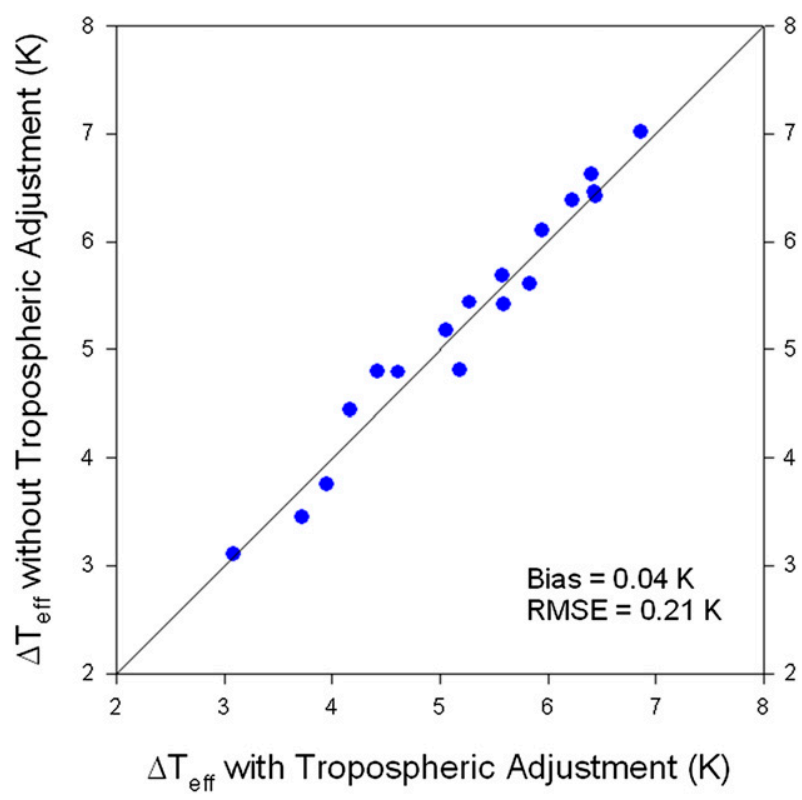

FIG. 14. Impact of isolating tropospheric adjustments from the corresponding tropospheric feedbacks on the estimate of effective climate sensitivity $\Delta T_{\text {eff }}$ for the CMIP5 abrupt $4 \times \mathrm{CO}_{2}$ experiment [refer to Eq. (6)]. The horizontal axis denotes the effective climate sensitivity computed by treating the tropospheric adjustments as part of the total forcing. In contrast, the vertical axis corresponds to the case wherein the tropospheric adjustments are included as part of the corresponding feedbacks. The one-to-one line is shown for reference.

small estimates of cloud adjustment. Previous studies derived the cloud adjustment estimates from fixed SST experiments in which land surface warming is not constrained, implying that small but nonnegligible globalmean surface warming in fixed SST experiments can alias a surface-driven feedback response into estimates of the adjustments. Therefore, correcting for the bias introduced from this global-mean surface warming is required for a more accurate quantification of tropospheric adjustments.

The spatial patterns of the tropospheric adjustments tend to oppose the radiative feedback. We argue that a substantial part of the spatial pattern of the adjustment is an artifact of the methodology and can be explained in terms of a linear but spatially varying feedback with no adjustment operating in response to spatially inhomogeneous warming. Even when assuming that the global-mean estimates of the tropospheric adjustments are valid, it was demonstrated that neglecting them introduces little uncertainty in estimates of the total forcing, feedback, or effective climate sensitivity relative to the intermodel spread in these values. Therefore, this radiative kernelbased methodology can be applicable to more realistic forcing scenarios.

Intermodel spread in the global-average tropospheric adjustment results in a reduced strength of multimodel mean. However, it does not mean that tropospheric adjustments are not important, because non- $\mathrm{CO}_{2}$ forcings (e.g., aerosols) are known to exert significant cloud adjustments in the troposphere, which in turn may have an important implication for diagnosing climate sensitivity from the observed historical record (e.g., Zelinka et al. 2014; Sherwood et al. 2015).

As noted in previous studies (e.g., Dufresne and Bony 2008; Andrews et al. 2012; Forster et al. 2013; Vial et al. 2013), intermodel differences in climate sensitivity are dominated by uncertainties in the feedback processes in the troposphere rather than uncertainties in direct radiative forcing, rapid radiative adjustments, or heat uptake. Because of an anticorrelation between radiative feedbacks and total forcing across models, however, intermodel spread in the actual effective climate sensitivity is reduced compared to that arising from uncertainties in the radiative feedbacks (Kiehl 2007; Knutti 2008; Andrews et al. 2012; Forster et al. 2013). In our study, this compensation disappears if tropospheric adjustments are excluded from the total forcing. While the analysis presented here highlights how inhomogeneous patterns of surface warming can explain part of the pattern of inferred tropospheric adjustments, more recent studies using aquaplanet simulations with uniform warming also find an anticorrelation between radiative feedbacks and radiative forcing from $\mathrm{CO}_{2}$, which is driven by the compensation between cloud feedback and cloud adjustment (Ringer et al. 2014). The caveats regarding tropospheric adjustments presented here cannot explain the results of Ringer et al. (2014), and more research is needed to fully understand those results.

Acknowledgments. We thank Dr. Karen Shell, two anonymous reviewers, and the editor for their constructive and valuable comments, which led to an improved version of the manuscript. We acknowledge the World Climate Research Programme's Working Group on Coupled Modeling, which is responsible for CMIP, and we thank the climate modelling groups (listed in Table S1 of this study) for producing and making available their model output. For CMIP, the U.S. Department of Energy's Program for Climate Model Diagnosis and Intercomparison provides coordinating support and led development of software infrastructure in partnership with the Global Organization for Earth System Science Portals. This research was supported by a grant from the NASA ROSES program and the NOAA Climate Program Office.

\section{REFERENCES}

Andrews, T., 2014: Using an AGCM to diagnose historical effective radiative forcing and mechanisms of recent decadal 
climate change. J. Climate, 27, 1193-1209, doi:10.1175/ JCLI-D-13-00336.1.

— , and P. M. Forster, 2008: $\mathrm{CO}_{2}$ forcing induces semi-direct effects with consequences for climate feedback interpretations. Geophys. Res. Lett., 35, L04802, doi:10.1029/ 2007 GL032273.

— J. M. Gregory, M. J. Webb, and K. E. Taylor, 2012: Forcing, feedbacks and climate sensitivity in CMIP5 coupled atmosphereocean climate models. Geophys. Res. Lett., 39, L09712, doi:10.1029/ 2012 GL051607.

Armour, K. C., C. M. Bitz, and G. H. Roe, 2013: Time-varying climate sensitivity from regional feedbacks. J. Climate, 26, 4518-4534, doi:10.1175/JCLI-D-12-00544.1.

Block, K., and T. Mauritsen, 2013: Forcing and feedback in the MPI-ESM-LR coupled model under abruptly quadrupled $\mathrm{CO}_{2}$. J. Adv. Model. Earth Syst., 5, 676-691, doi:10.1002/ jame.20041.

Bony, S., and J.-L. Dufresne, 2005: Marine boundary layer clouds at the heart of tropical cloud feedback uncertainties in climate models. Geophys. Res. Lett., 32, L20806, doi:10.1029/ 2005 GL023851.

— uate climate change feedback processes? J. Climate, 19, 34453482, doi:10.1175/JCLI3819.1.

Cess, R. D., and Coauthors, 1990: Intercomparison and interpretation of climate feedback processes in 19 atmospheric general circulation models. J. Geophys. Res., 95, 1660116615, doi:10.1029/JD095iD10p16601.

Chung, E.-S., B. J. Soden, and B.-J. Sohn, 2010: Revisiting the determination of climate sensitivity from relationships between surface temperature and radiative fluxes. Geophys. Res. Lett., 37, L10703, doi:10.1029/2010GL043051.

,,---1, and J. Schmetz, 2011: Model-simulated humidity bias in the upper troposphere and its relation to the large-scale circulation. J. Geophys. Res., 116, D10110, doi:10.1029/ 2011JD015609.

,$- \ldots$, and A. C. Clement, 2012: Diagnosing climate feedbacks in coupled ocean-atmosphere models. Surv. Geophys., 33, 733-744, doi:10.1007/s10712-012-9187-x.

Collins, W. D., and Coauthors, 2006: Radiative forcing by wellmixed greenhouse gases: Estimates from climate models in the Intergovernmental Panel on Climate Change (IPCC) Fourth Assessment Report (AR4). J. Geophys. Res., 111, D14317, doi:10.1029/2005JD006713.

Colman, R. A., 2003: A comparison of climate feedbacks in general circulation models. Climate Dyn., 20, 865-873, doi:10.1007/ s00382-003-0310-z.

_- and B. J. McAvaney, 2011: On tropospheric adjustment to forcing and climate feedbacks. Climate Dyn., 36, 1649-1658, doi:10.1007/s00382-011-1067-4.

__ , and L. I. Hanson, 2013: On atmospheric radiative feedbacks associated with climate variability and change. Climate Dyn., 40, 475-492, doi:10.1007/s00382-012-1391-3.

Dalton, M. M., and K. M. Shell, 2013: Comparison of short-term and long-term radiative feedbacks and variability in twentiethcentury global climate model simulations. J. Climate, 26, 10 051-10 070, doi:10.1175/JCLI-D-12-00564.1.

Dufresne, J.-L., and S. Bony, 2008: An assessment of the primary sources of spread of global warming estimates from coupled atmosphere-ocean models. J. Climate, 21, 5135-5144, doi:10.1175/ 2008JCLI2239.1.

Feldl, N., and G. H. Roe, 2013: Four perspectives on climate feedbacks. Geophys. Res. Lett., 40, 4007-4011, doi:10.1002/grl.50711.
Forster, P. M., and Coauthors, 2011: Evaluation of radiation scheme performance within chemistry climate models. J. Geophys. Res., 116, D10302, doi:10.1029/2010JD015361.

— , T. Andrews, P. Good, J. M. Gregory, L. S. Jackson, and M. Zelinka, 2013: Evaluating adjusted forcing and model spread for historical and future scenarios in the CMIP5 generation of climate models. J. Geophys. Res., 118, 1139-1150, doi:10.1002/ jgrd.50174.

Gregory, J. M., and M. Webb, 2008: Tropospheric adjustment induces a cloud component in $\mathrm{CO}_{2}$ forcing. J. Climate, 21, 5871, doi:10.1175/2007JCLI1834.1.

— forcing and climate sensitivity. Geophys. Res. Lett., 31, L03205, doi:10.1029/2003GL018747.

Hansen, J., and Coauthors, 2005: Efficacy of climate forcings. J. Geophys. Res., 110, D18104, doi:10.1029/2005JD005776.

Held, I. M., M. Winton, K. Takahashi, T. Delworth, F. Zeng, and G. K. Vallis, 2010: Probing the fast and slow components of global warming by returning abruptly to preindustrial forcing. J. Climate, 23, 2418-2427, doi:10.1175/2009JCLI3466.1.

Huang, X., X. Chen, B. J. Soden, and X. Liu, 2014: The spectral dimension of longwave feedbacks in the CMIP3 and CMIP5 experiments. Geophys. Res. Lett., 41, 7830-7837, doi:10.1002/ 2014 GL061938.

Jonko, A. K., K. M. Shell, B. M. Sanderson, and G. Danabasoglu, 2012: Climate feedbacks in CCSM3 under changing $\mathrm{CO}_{2}$ forcing. Part I: Adapting the linear radiative kernel technique to feedback calculations for a broad range of forcings. J. Climate, 25, 5260-5272, doi:10.1175/ JCLI-D-11-00524.1.

Kiehl, J. T., 2007: Twentieth century climate model response and climate sensitivity. Geophys. Res. Lett., 34, L22710, doi:10.1029/ 2007 GL031383.

Klein, S. A., and C. Jakob, 1999: Validation and sensitivities of frontal clouds simulated by the ECMWF model. Mon. Wea. Rev., 127, 2514-2531, doi:10.1175/1520-0493(1999)127<2514: VASOFC $>2.0 . \mathrm{CO} ; 2$.

Knutti, R., 2008: Why are climate models reproducing the observed global surface warming so well? Geophys. Res. Lett., 35, L18704, doi:10.1029/2008GL034932.

Li, G., and S.-P. Xie, 2014: Tropical biases in CMIP5 multimodel ensemble: The excessive equatorial Pacific cold tongue and double ITCZ problems. J. Climate, 27, 1765-1780, doi:10.1175/ JCLI-D-13-00337.1.

Murphy, J. M., 1995: Transient response of the Hadley Centre coupled ocean-atmosphere model to increasing carbon dioxide. Part III: Analysis of global-mean response using simple models. J. Climate, 8, 496-514, doi:10.1175/1520-0442(1995)008<0496: TROTHC $>2.0 . \mathrm{CO} ; 2$.

Ringer, M. A., T. Andrews, and M. J. Webb, 2014: Global-mean radiative feedbacks and forcing in atmosphere-only and coupled atmosphere-ocean climate change experiments. Geophys. Res. Lett., 41, doi:10.1002/2014GL060347.

Senior, C. A., and J. F. B. Mitchell, 2000: The time-dependence of climate sensitivity. Geophys. Res. Lett., 27, 2685-2688, doi:10.1029/2000GL011373.

Shell, K. M., J. T. Kiehl, and C. A. Shields, 2008: Using the radiative kernel technique to calculate climate feedbacks in NCAR's Community Atmospheric Model. J. Climate, 21, 2269-2282, doi:10.1175/2007JCLI2044.1.

Sherwood, S. C., S. Bony, O. Boucher, C. Bretherton, P. M. Forster, J. M. Gregory, and B. Stevens, 2015: Adjustments in the forcing-feedback framework for understanding climate 
change. Bull. Amer. Meteor. Soc., 96, 217-228, doi:10.1175/ BAMS-D-13-00167.1.

Soden, B. J., and I. M. Held, 2006: An assessment of climate feedbacks in coupled ocean-atmosphere models. J. Climate, 19, 3354-3360, doi:10.1175/JCLI3799.1.

, and G. A. Vecchi, 2011: The vertical distribution of cloud feedback in coupled ocean-atmosphere models. Geophys. Res. Lett., 38, L12704, doi:10.1029/2011GL047632.

— , A. J. Broccoli, and R. S. Hemler, 2004: On the use of cloud forcing to estimate cloud feedback. J. Climate, 17, 3661-3665, doi:10.1175/1520-0442(2004)017<3661:OTUOCF >2.0.CO;2.

_ , I. M. Held, R. Colman, K. M. Shell, J. T. Kiehl, and C. A. Shields, 2008: Quantifying climate feedbacks using radiative kernels. J. Climate, 21, 3504-3520, doi:10.1175/2007JCLI2110.1.

Taylor, K. E., R. J. Stouffer, and G. A. Meehl, 2012: An overview of CMIP5 and the experiment design. Bull. Amer. Meteor. Soc., 93, 485-498, doi:10.1175/BAMS-D-11-00094.1.

Vial, J., J.-L. Dufresne, and S. Bony, 2013: On the interpretation of inter-model spread in CMIP5 climate sensitivity estimates. Climate Dyn., 41, 3339-3362, doi:10.1007/s00382-013-1725-9.
Webb, M. J., F. H. Lambert, and J. M. Gregory, 2013: Origins of differences in climate sensitivity, forcing and feedback in climate models. Climate Dyn., 40, 677-707, doi:10.1007/ s00382-012-1336-x

Zelinka, M. D., S. A. Klein, and D. L. Hartmann, 2012: Computing and partitioning cloud feedbacks using cloud property histograms. Part I: Cloud radiative kernels. J. Climate, 25, 37153735, doi:10.1175/JCLI-D-11-00248.1.

,,-- K. E. Taylor, T. Andrews, M. J. Webb, J. M. Gregory, and P. M. Forster, 2013: Contributions of different cloud types to feedbacks and rapid adjustments in CMIP5. J. Climate, 26, 5007-5027, doi:10.1175/JCLI-D-12-00555.1.

— T. Andrews, P. M. Forster, and K. E. Taylor, 2014: Quantifying components of aerosol-cloud-radiation interactions in climate models. J. Geophys. Res., 119, 7599-7615, doi:10.1002/ 2014JD021710.

Zhang, M. H., J. J. Hack, J. T. Kiehl, and R. D. Cess, 1994: Diagnostic study of climate feedback processes in atmospheric general circulation models. J. Geophys. Res., 99, 5525-5537, doi:10.1029/93JD03523. 